\title{
Selective mortality on early life-history traits of a temperate reef fish
}

\author{
by \\ Phoebe Katherine Jemima Caie
}

\begin{abstract}
A thesis
submitted to the Victoria University of Wellington in partial fulfilment of the requirements for the degree of Master of Science in Marine Biology
\end{abstract}

Victoria University of Wellington

2016 


\begin{abstract}
Variability in recruitment and early life-history traits is widespread in many marine organisms. Phenotypic variation is particularly prevalent in the early life-history stages (e.g., larvae and juveniles) of reef fish, and provides the basis for selective mortality on growth and size-related traits, with important ecological and evolutionary consequences. Recruitment variability can alter the effective densities experienced by these early life stages, raising additional questions about the interplay between selection and density-dependent processes. While many examples of growth- and sizeselective mortality have been documented for young reef fish (typically caused by predators), few studies consider how the strength and/or direction of selective mortality changes with ontogeny, or how these patterns may be mediated by density. I explore spatio-temporal variability in early life-history traits of the common triplefin, Forsterygion lapillum, using metrics derived from otoliths (a re-analysis of two previously collected data sets). I evaluate patterns of variation in traits with respect to early life-history stage (either larvae or post-settlement juveniles) and document shifts in the distributions of traits that are consistent with selective mortality favouring slower growing individuals. I conclude that a cohort of juveniles (sampled after settlement) was comprised of individuals that were smaller at hatch and grew slowly throughout the pelagic larval period relative to a cohort of larvae (sampled prior to settlement). I then conducted an experiment using a set of mesocosms to evaluate whether selective mortality on early life-history traits in common triplefin could be caused by a natural predator, the variable triplefin, Forsterygion varium. Specifically, I exposed groups of fish of each stage to a pair of predators and I used otoliths to reconstruct the traits of fish that survived versus fish that were consumed (i.e., I recovered otoliths from the guts of predators). Selection trials were conducted across realistic density gradients for each developmental stage. Fish size was negatively correlated with relative fitness for larvae (indicating larger fish were consumed preferentially by predators) but not for juveniles (where no size-selective mortality was observed). These patterns were consistent across the range of densities evaluated. Both larvae and juveniles experienced significant selection against fast larval growth (estimated from growth increments in
\end{abstract}


otoliths), and the strength of selection was inversely related to density (i.e., strongest at lower densities, weakest at higher densities). However, juveniles also experienced selective predation for fast growth at the larval-juvenile transition. As with larval growth, selection was strongest at lower densities and weakest at higher densities. Collectively, these results suggest that predators may preferentially target larger larvae, and faster growing individuals regardless of developmental stage. However, this effect may be mediated by density, such that the strongest selection occurs during low recruitment. Density-dependent selection could explain how faster growing individuals can survive this vulnerable stage. These results provide evidence for carry-over effects of larval growth on juvenile survival, and suggest conspecific density should be considered when evaluating patterns of selective mortality. 


\section{Acknowledgements}

Firstly, I would like to thank my supervisor Professor Jeff Shima for his support and encouragement during my Master's. Your continuous advice and patience has been wonderful, and I've thoroughly enjoyed the freedom to run my own project. I'm incredibly grateful for the funding provided by the Marsden grant award to Jeff Shima; this thesis would not have been possible without it. And to the Shima lab group, thank you for your assistance in the field and laboratory. In particular, Ben, Becky, Snout and Paul - you have been amazing lab mates, I'm so grateful for all the time you spent helping me work through problems.

Raphael, thank you for your love and support over the past few years. I'm a little disappointed I couldn't convince you to switch from microbiology (or was it cell biology?) to ecology, but I guess not everyone can live the dream. Your kind words and competitive spirit have constantly inspired me.

Ben and Becky, my partners in crime, thank you for all your help boating and diving, your company during long days in the microscope room, and all those ridiculous pranks. It has been an absolute pleasure working with the two of you. Megan, I've enjoyed our morning (and afternoon) coffee rituals - hopefully we can keep this tradition going! And thanks to Tracey and Alix for all your advice on surviving post-graduate life, I would have been lost without it. Thanks to you all for being such great friends.

To the VUCEL community, thanks for making my Master's such an enjoyable experience. The countless barbeques, coffee dates, morning teas and dinner parties have been so much fun, and I'm glad to be part of such a fantastic group of people. Thank you to the technicians - Snout, Dan and John - for your tremendous support and assistance during my time at the lab. Technicians are certainly the unsung heroes of experimental design! Finally, my parents and siblings - you may have never understood what I was talking about, but you always encouraged me to do my best and for that I am thankful. 


\section{Table of Contents}

Abstract

Acknowledgements iv

Table of Contents $\quad$ v

List of Figures vii

1 General introduction $\quad 1$

1.1 Causes of variability in recruitment rates and phenotypic traits $\quad 1$

1.2 Consequences of variability in recruitment rates and phenotypic traits 3

$\begin{array}{ll}1.3 \text { Study species } & 6\end{array}$

$\begin{array}{ll}1.4 \text { Thesis research } & 6\end{array}$

2 Spatio-temporal variability in the early life-history of a temperate reef fish 8

2.1 Introduction $\quad 8$

2.2 Methods 11

2.2.1 Spatio-temporal variability in early life-history traits 13

2.2.2 Differences in early life-history traits between life stages $\quad \mathbf{1 4}$

2.2.3 Variability of early life-history traits as a function of density $\quad 14$

$\begin{array}{ll}2.3 \text { Results } & 14\end{array}$

2.3.1 Spatio-temporal variability in early life-history traits $\quad \mathbf{1 5}$

2.3.2 Differences in early life-history traits between life stages $\quad 19$

2.3.3 Variability of early life-history traits as a function of density 19

$\begin{array}{lr}2.4 \text { Discussion } & 21\end{array}$

2.4.1 Variability in early life-history traits 21 
2.4.3 Conclusions

3 Predator-induced selective mortality in the early life stages of a temperate reef fish

3.1 Introduction

3.2 Methods 29

$\begin{array}{ll}\text { 3.2.1 Study species } & 29\end{array}$

$\begin{array}{ll}\text { 3.2.2 } & \text { Fish collections } \\ \end{array}$

3.2.3 Mesocosms to evaluate selective predation $\quad 30$

3.2.4 Otolith analyses to evaluate selection based on growth histories $\mathbf{3 1}$

$\begin{array}{lll}3.3 \text { Results } & 33\end{array}$

3.3.1 Selective predation as a function of size and density 33

3.3.2 Selective predation as a function of age, larval growth history, $\quad \mathbf{3 5}$ and density

$\begin{array}{ll}3.4 \text { Discussion } & 38\end{array}$

3.4.1 Selective mortality on larval stage F. lapillum 39

3.4.2 Selective mortality on juvenile stage $F$. lapillum 40

$\begin{array}{lll}\text { 3.4.3 Conclusions } & 41\end{array}$

4 General conclusions 43

$\begin{array}{ll}4.1 \text { Summary of findings } & 43\end{array}$

$\begin{array}{ll}4.2 & \text { Future directions }\end{array}$

$\begin{array}{lr}\text { Appendix } & 47\end{array}$

$\begin{array}{ll}\text { Bibliography } & 48\end{array}$ 


\section{List of Figures}

\section{General introduction}

1.1 Larval and juvenile stage Forsterygion lapillum

2 Spatio-temporal variability in the early life-history of a temperate reef fish

2.1 Sample sites for larval and juvenile stage Forsterygion lapillum

2.2 Temporal and spatial variation in early life-history traits of larval stage Forsterygion lapillum

2.3 Temporal and spatial variation in early life-history traits of juvenile stage Forsterygion lapillum

2.4 Variation in early life-history traits between larval and juvenile stage 20 Forsterygion lapillum

2.5 Relationship between early larval growth and density of larval Forsterygion lapillum

3 Predator-induced selective mortality in the early life stages of a temperate reef fish

3.1 Dissected Forsterygion varium and recovered Forsterygion lapillum sagittal otolith

3.2 Relative fitness for larval and juvenile stage Forsterygion lapillum as a function of standardised size and larval growth rate

3.3 Relative fitness for juvenile stage Forsterygion lapillum as a function of standardised late larval growth 



\section{Chapter 1 - General introduction}

Many marine organisms have a bipartite life cycle with a distinct benthic adult and pelagic larval stage (Thorson 1950, Roughgarden et al. 1988, Kaufman et al. 1992, Bonhomme and Planes 2000, Cowen and Sponaugle 2009, Marshall et al. 2012, Kimirei et al. 2013). Mortality during the larval stage is extremely high (Leak and Houde 1987, Gosselin and Qian 1997, Hunt and Scheibling 1997); predation and starvation are considered the two most important sources of mortality for fish eggs and larvae (Leak and Houde 1987, Bailey and Houde 1989, Leggett and Deblois 1994, Bachiller et al. 2015). Dispersal and survival of larvae are important for determining larval supply, which in turn is important for recruitment strength (Roughgarden et al. 1988, Jones 1990, Grosberg and Levitan 1992, Caley et al. 1996, Swearer et al. 1999, Hixon et al. 2012, Neumann et al. 2014), adult population densities (Hixon 1998, Hare 2014), and demographic and genetic connectivity (Kritzer and Sale 2004, Hauser and Carvalho 2008, Shima et al. 2010, Le Corre et al. 2015, Shima et al. 2015). Predicting recruitment variability remains a central focus for both fundamental and applied ecological studies (Bjørnstad et al. 1999, Siegel et al. 2008, Whitten et al. 2013, Bastrikin et al. 2014, Hare 2014), and may improve management of marine stocks.

\section{1 - Causes of variability in recruitment rates and phenotypic traits}

Understanding recruitment variability has been the driving goal for fisheries science over the past century (Hjort 1914, Caley et al. 1996, Bjørnstad et al. 1999, Bastrikin et al. 2014). Larval supply is driven by both the quantity and quality of individuals, which in turn is influenced by parental effects, developmental environments, and mortality during early life stages (reviewed in Fogarty et al. 1991, Miller et al. 1991, Sponaugle et al. 2002, Lecchini 2003, Houde 2008, Siegel et al. 2008, Hare 2014). Reproductive output of adults is an obvious starting point when considering larval variability. Timing of reproduction, as well as the number and condition of eggs produced are known to influence the survival of eggs and larvae immediately after hatching (Hjort 1914, Blanchard et al. 2003, Huss et al. 2007, Donelson et al. 2008, Maddams and McCormick 
2012, Donelan and Trussell 2015, Moore et al. 2015). The condition of both mother and father will also play a role in determining success of offspring (Kerrigan 1997, Berkeley et al. 2004, McCormick 2006, Hixon et al. 2014, Saenz-Agudelo et al. 2015). Marine organisms exhibit substantial phenotypic plasticity in response to environmental factors, such as temperature and food (Blaxter and Holliday 1963, Fisher and Pearcy 1988, Booth and Hixon 1999, Beukema and Dekker 2014) and other abiotic conditions (Sponaugle and Pinkard 2004a, b, Sponaugle and Grorud-Colvert 2006, Chaparro et al. 2014, Delorme and Sewell 2014). Developmental trajectories will be influenced by these conditions (Cushing 1975, Hadfield and Strathmann 1996, Baumann et al. 2006, Shima and Swearer 2016), and dispersal (be it active or passive) will determine which environments individuals will encounter (Lough et al. 2005, Cowen and Sponaugle 2009, Boucher et al. 2013, Petrik et al. 2014, Pfaff et al. 2015). The interaction between organisms and their environment will determine success, and so phenotypic traits will determine quality of an individual. As such, the environment larvae develop in can have significant impacts on survival and recruitment strength (Pepin 1991, Campana 1996, Jenkins and King 2006, Shima and Swearer 2009a, b, Bauer and Miller 2010, Shima and Swearer 2010, Boucher et al. 2013, Johnson et al. 2014).

Growth and morphology of poikilothermic organisms are strongly regulated by temperature and food availability (Fisher and Pearcy 1988, Houde 1989, Hovenkamp 1990, Houde and Zastrow 1993, McCormick and Moloney 1995, Grorud-Colvert and Sponaugle 2011, Fouzai et al. 2015, Günther et al. 2015), and recruitment strength has also been linked to sea surface temperature and plankton production (Campana 1996, Beaugrand et al. 2003, Platt et al. 2003, Durant et al. 2007, Castonguay et al. 2008). Anderson (Anderson 1988) synthesised the hypotheses concerning links between growth, size and recruitment strength into one 'growth-mortality' hypothesis. This hypothesis consists of two main concepts: 1) larger individuals are less susceptible to size-selective mortality (via starvation and predation) and 2) faster growing individuals are cumulatively less vulnerable to size-selective mortality as they can attain a sizerefuge more quickly. Bailey and Houde (Bailey and Houde 1989) proposed predators as the agent of selective mortality on these traits during early life stages. The growth- 
mortality hypothesis originally garnered considerable support (e.g., Post and Prankevicius 1987, Miller et al. 1988, Pepin et al. 1992, Cargnelli and Gross 1996, Hare and Cowen 1997, Sogard 1997), but many studies have also found little or opposing evidence for the positive effects of size and growth on survival (e.g., Good et al. 2001, Munch and Conover 2003, Biro et al. 2004, Holmes and McCormick 2006, Biro and Post 2008, Carlson et al. 2008, Holmes and McCormick 2009, Fontes et al. 2010, Sponaugle et al. 2011). The relationship between growth rates and recruitment strength is not always consistent (Booth 1995, Meekan and Fortier 1996, Suthers 1998, Sponaugle et al. 2006, Robert et al. 2007, Grorud-Colvert and Sponaugle 2011, Rankin and Sponaugle 2011b) and there is still considerable variation in findings between studies. Regardless of the cause, there is substantial variation in recruitment strength and the phenotypes of settlers.

\section{2 - Consequences of variability in recruitment rates and phenotypic traits}

Larval growth is often positively correlated with recruitment (e.g., Bergenius et al. 2002, Wilson and Meekan 2002, Jenkins and King 2006, Fontes et al. 2010), but determining the causal mechanism behind these patterns is difficult. Growth and size are clearly linked, and size-selective mortality at settlement may limit the number of recruits at a site. Predators have been identified as the leading cause of mortality for many reef fish (Doherty and Sale 1985, Shima 2002, Steele and Forrester 2002, Webster 2002, Doherty et al. 2004), with upwards of $50 \%$ of newly settled fish removed within the first few days (Planes and Lecaillon 2001, Almany and Webster 2005, Heinlein et al. 2010). Because of this extreme bottleneck and the variability in relative fitness of individuals at settlement, predation has the potential to be selective on growth or size traits. Selective predation has been shown to structure prey populations in many other systems (Paine 1974, 1976, Carr et al. 2002, Bodin et al. 2012, Castorani and Hovel 2015), and can play an important role in shaping the phenotypes and life-history patterns of prey (Reznick 1982, Reznick and Endler 1982, Reznick 1989, Reznick et al. 1990, Conover and Munch 2002, Day et al. 2002, Losos et al. 2004, Perez and Munch 2010, Davenport et al. 2014, Bijleveld et al. 2015). In some instances, smaller larvae or juveniles are removed from the cohort (Planes and Lecaillon 2001), and fast growth is beneficial. However, as fast growth and 
enhanced development may result in larvae settling younger and smaller (Fontes et al. 2010, Rankin and Sponaugle 2014), size selection for larger individuals may favour slower growing individuals. Size can play an important role in determining social structure for reef fish, and access to food or refuge may be monopolised by larger individuals (Nicieza and Metcalfe 1999, Booth and Beretta 2004). If smaller individuals are unable to feed effectively and are also consigned to riskier habitats, then mortality will be selective on smaller individuals (leading to a negative correlation between mortality rates and fish size). Alternatively, increased foraging rates can enhance predation risks, resulting in selection against larger or faster growing individuals (Billerbeck et al. 2001, Lankford et al. 2001, Munch and Conover 2003, Stoks et al. 2005, Sundström et al. 2005). As fish body condition (e.g. weight or lipid content) and growth can be correlated (Hamilton 2008, Hamilton et al. 2008), growth-selective mortality can occur if predators select for (Booth and Hixon 1999, Booth and Beretta 2004, GrorudColvert and Sponaugle 2006, Johnson 2008) or against (Hoey and McCormick 2004, Dibattista et al. 2007) individuals in better condition. Because the quality of individuals is determined by their phenotypes, cohort quality will depend on the phenotypic composition of the cohort. Phenotypic heterogeneity provides the opportunity for selection to occur and as such, selective mortality can influence the success of settlers, recruitment strength and population density.

Many metrics of juvenile (i.e., post-larval) quality are determined by experiences in the larval stage (i.e., carry-over effects). Consequently, the developmental history of an individual can strongly influence its future success. Studies on both invertebrate (Pechenik et al. 1998, Phillips 2002, Marshall et al. 2003a, Marshall et al. 2003b, Pechenik 2006, Crean et al. 2011, Allen and Marshall 2014, Chaparro et al. 2014, Delorme and Sewell 2014) and vertebrate (Grorud-Colvert and Sponaugle 2006, Pechenik 2006, Gagliano et al. 2007, Hamilton 2008, Hamilton et al. 2008, Lonnstedt and McCormick 2011, Johnson et al. 2012, Block and Steele 2014, Bowen et al. 2015, Johnson et al. 2015, Plard et al. 2015) organisms have found that an individual's early experiences can influence success at both juvenile and adult stages. For both temperate and tropical reef fishes, survival at settlement has been linked to various early life-history 
characteristics such as size-at-hatch (Vigliola and Meekan 2002, Macpherson and Raventos 2005, Raventos and Macpherson 2005), size-at-settlement (Tupper and Boutilier 1995, Campana 1996, Cargnelli and Gross 1996, McCormick and Hoey 2004, Rankin and Sponaugle 2011a, Block and Steele 2014), and growth rates during the larval and/or juvenile stage (Tupper and Boutilier 1995, Campana 1996, Dahlgren and Eggleston 2000, Bergenius et al. 2002, Shima and Findlay 2002, Vigliola and Meekan 2002, McCormick and Hoey 2004, Gagliano et al. 2007, Crean et al. 2011, Rankin and Sponaugle 2011b). Researchers should consider how selection on these traits may change with ontogeny, and there is substantial evidence that it does (Schluter et al. 1991, Hoekstra et al. 2001, Searcy and Sponaugle 2001, Almany 2004, Gagliano et al. 2007, Johnson and Hixon 2010, D'Alessandro et al. 2013, Sun et al. 2015). Phenotypes that are successful during one life stage may have reduced fitness at the next, and this is likely a result of changes in selective pressures an individual experiences as they move from the pelagic to benthic environment.

It is also important to consider the effect of recruitment strength on post-settlement processes. Reef fish populations are often controlled by density-dependent growth and mortality (Forrester 1990, Booth 1995, Forrester 1995, Tupper and Boutilier 1995, Shima 2001b, Lorenzen and Enberg 2002, Shima 2002), and elevated recruitment may have repercussions after settlement. Larvae and juveniles may be attracted to habitat where adults are present, but growth and survival may be reduced due to increased competition or mortality (Forrester 1995, Tupper and Boutilier 1995, Almany 2004, Gårdmark et al. 2006, Rankin and Sponaugle 2014). Again, the primary cause of densitydependent mortality for reef fish is often attributed to the interaction between predators and refuge availability. While variability in mortality due to conspecific density, habitat complexity and predator assemblages has been studied thoroughly (Gilliam and Fraser 1987, Hixon and Beets 1993, Tupper and Boutilier 1997, Beukers and Jones 1998, Nemeth 1998, Shima 2001a, Holbrook et al. 2002b, a, Biro et al. 2003a, c, Holbrook and Schmitt 2003, Shima and Osenberg 2003, Almany 2004, Doherty et al. 2004, Forrester and Steele 2004, Hixon and Jones 2005, Johnson 2006, 2007, Shima et al. 2008, Hixon et al. 2012, Felix-Hackradt et al. 2013, Stier et al. 2013, Carroll et al. 2015), 
their effects on selective mortality are often not considered (however, see Brunton and Booth 2003, Holmes and McCormick 2006, Johnson 2008, Samhouri et al. 2009, Fontes et al. 2010, Smith and Shima 2011, Wormald et al. 2013, Hansen and Beauchamp 2014, Johnson et al. 2014, Murphy et al. 2014). Since predation has been shown to be both selective and density-dependent, patterns of selection on newly settled fish have the potential to change with recruitment strength.

\section{3 - Study species}

The common triplefin (Forsterygion lapillum) provides an excellent study species for experimental evaluations of size- or growth-selective mortality at settlement. Forsterygion lapillum is a small bodied temperate reef fish, and is abundant throughout most of New Zealand's coastal shallow waters (Francis 2001, Feary and Clements 2006). Individuals hatch from eggs laid on cobbles, and develop as pelagic larvae for 1-3 months (Shima and Swearer 2009a). Larvae (Fig. 1.1A) settle to fronds of macroalgae and then move to cobble habitat as juveniles (Fig. 1.1B) (McDermott and Shima 2006), where they remain through adulthood. Larval and juvenile stages of F. lapillum vary in early lifehistory traits (e.g., size, age, growth history, condition), and previous work (Shima and Swearer 2010, Noonburg et al. 2015, Shima et al. 2015) has shown that these traits can influence survival later in life. Recruitment of larval and juvenile triplefins is also variable (Swearer and Shima 2010, Shima and Swearer 2016), so young triplefins potentially experience selection over a range of densities.

\section{4 - Thesis research}

This thesis had two main aims: 1) to describe variability in recruitment and early lifehistory traits for larval and juvenile stages of $F$. lapillum, and 2) to investigate the presence of selective mortality during this early life period. In Chapter 2, I compared early life-history traits between larval and juvenile $F$. lapillum, and across temporal and spatial scales within each age group. In Chapter 3, I ran separate predation trials for larvae and juveniles over a range of natural densities, and compared the size and growth history of consumed and unconsumed triplefins. Data chapters have been written in the format of independent manuscripts to facilitate submission to peer-reviewed journals, 
and consequently they have their own specific Introductions and Discussion sections.

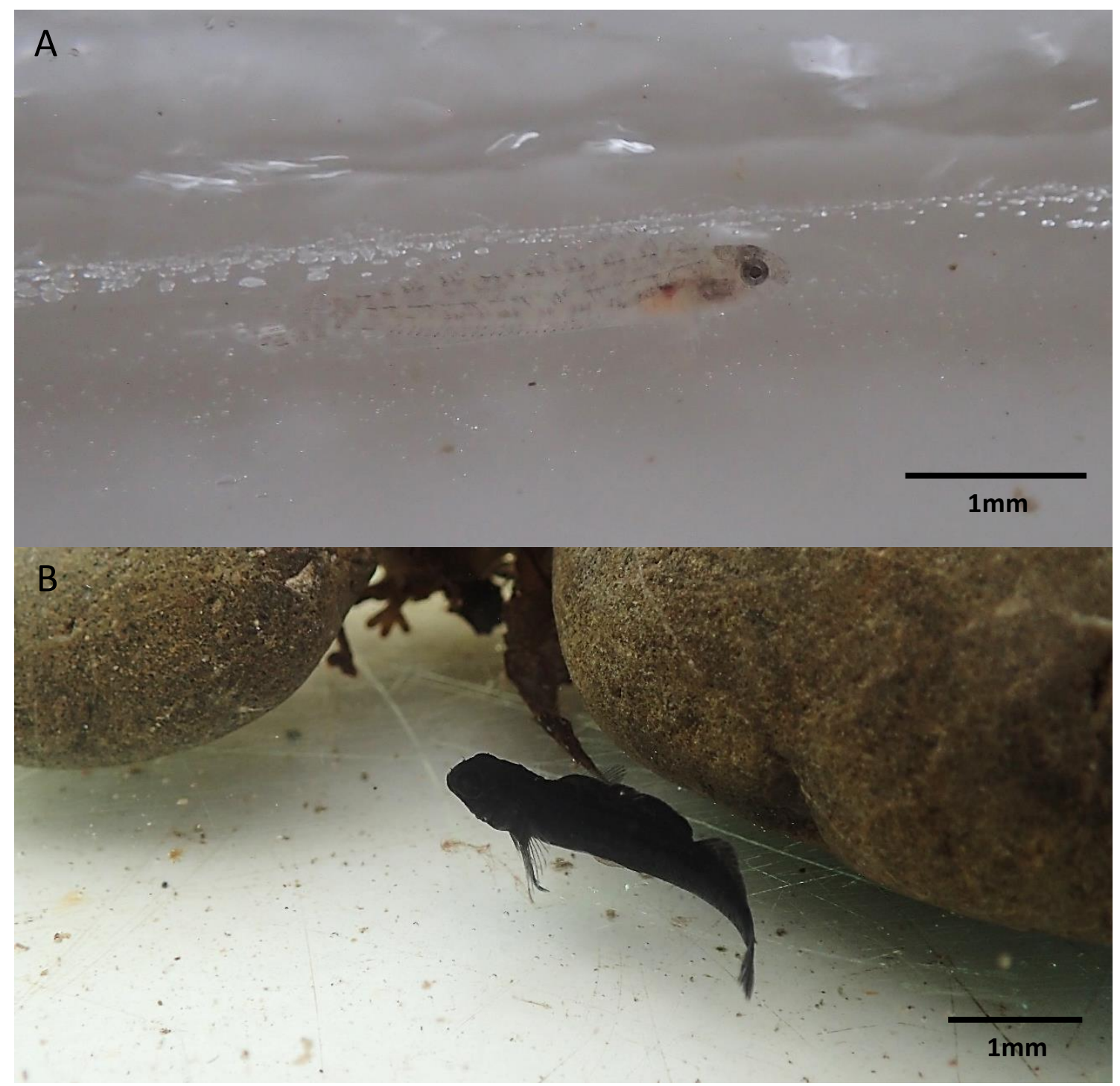

Figure 1.1: A) A larval Forsterygion lapillum. Their translucent body and lack of pigments are classic characteristics of a pelagic larva. B) A juvenile Forsterygion lapillum. Juveniles gain colouration in a matter of hours after settlement, and become more adult-like in appearance. Photograph credit: Phoebe Caie. 


\section{Chapter 2 - Spatio-temporal variability in the early life-history of a temperate reef fish}

\section{1 - Introduction}

Marine organisms typically have complex life-histories with distinct pelagic larval, and benthic juvenile and adult stages (Thorson 1950, Roughgarden et al. 1988, Kaufman et al. 1992, Bonhomme and Planes 2000, Cowen and Sponaugle 2009, Marshall et al. 2012, Kimirei et al. 2013). Environmental conditions experienced by developing larvae can influence growth rates and phenotypes (Blaxter and Holliday 1963, Fisher and Pearcy 1988, Booth and Hixon 1999, Sponaugle and Pinkard 2004a, b, Sponaugle and GrorudColvert 2006, Beukema and Dekker 2014), both of which may determine the fitness of an individual. In recent years, the presence of carry-over effects, the influence of experiences from a previous life stage on a future one, has been found for both marine invertebrates (Pechenik et al. 1998, Phillips 2002, Marshall et al. 2003a, Marshall et al. 2003b, Pechenik 2006, Crean et al. 2011) and vertebrates (Grorud-Colvert and Sponaugle 2006, Pechenik 2006, Gagliano et al. 2007, Hamilton 2008, Hamilton et al. 2008, Lonnstedt and McCormick 2011, Johnson et al. 2012, Bowen et al. 2015, Johnson et al. 2015). As cohorts may be comprised of individuals with many different developmental trajectories, early life-history traits of recruits can be quite variable (Cushing 1975, Pepin 1991, Campana 1996, Hadfield and Strathmann 1996, Baumann et al. 2006, Jenkins and King 2006, Shima and Swearer 2009a, b, Bauer and Miller 2010, Shima et al. 2010, Boucher et al. 2013, Johnson et al. 2014, Shima and Swearer 2016). Understanding the causes and consequences of this variation remains a substantial knowledge gap for both fundamental and applied ecological studies (e.g., Bjørnstad et al. 1999, Wilson and Meekan 2001, 2002, Beaugrand et al. 2003, Siegel et al. 2008, Whitten et al. 2013, Bastrikin et al. 2014, Hare 2014).

Studies on early life-history traits, such as growth rates and body size, typically find substantial variation within and between cohorts (Houde 1989, Hadfield and Strathmann 1996, Searcy and Sponaugle 2000, Meekan et al. 2003, Sponaugle and 
Grorud-Colvert 2006, Sponaugle et al. 2006, Shima and Swearer 2009a, Shima and Swearer 2016). Although genetics clearly play a role in determining these traits, parental effects and developmental experiences can shape the growth and size of marine organisms. Parental effects are known to influence the development and condition of offspring, and survival after hatching may depend on yolk provisioning (McCormick 2006, Donelson et al. 2008), mate choice (Green and McCormick 2005, Donelson et al. 2008, Green 2008) or timing of reproduction (Cargnelli and Gross 1996, Burgess and Marshall 2014). For most marine organisms, metabolic demands and development trajectories can be altered by both food availability and temperature (Fisher and Pearcy 1988, Houde 1989, Hovenkamp 1990, Houde and Zastrow 1993, McCormick and Moloney 1995, Grorud-Colvert and Sponaugle 2011, Fouzai et al. 2015, Günther et al. 2015).

Variability in individual quality will have clear effects on individual performance, as some offspring will be better suited for competition or predator avoidance (Nicieza and Metcalfe 1999, Booth and Beretta 2004). For example, individuals that are larger may monopolise food patches and mates, or refuge from predators. An appreciation of variation within populations has led to the rise of individual based models (Bjørnstad and Hansen 1994, Benton et al. 2006, Giacomini et al. 2013), which aim to determine how the quantity and quality of individuals interact to influence population dynamics. In some instances, a smaller group of better quality individuals may actually outperform a larger group made up of poorer quality individuals in terms of population growth (Coulson et al. 2006, Burgess and Marshall 2011). As certain phenotypes may have disproportional future success (Shima et al. 2010, Burgess and Marshall 2011, Burgess et al. 2012, Shima and Swearer 2016), the proportion of different quality individuals could then play an important role in metapopulation connectivity and community stability.

While widespread, patterns of variability in early life-history traits are poorly understood for many marine species. As developmental conditions vary both spatially and temporally, early life-history traits will also differ. For many temperate fish species, regions with warmer and nutrient rich waters can elevate growth rates of developing 
larvae (Blaxter and Holliday 1963, Fisher and Pearcy 1988, Campana 1996, Booth and Hixon 1999, Castonguay et al. 2008). Temporal variability can arise as these conditions change from year to year, or even seasonally. Variation in early life-history traits may also be due to differences in life stages, which may be indicative of selective mortality. The potential for selection to occur is strongest when variability and mortality are highest; many reef fish are known to be variable in traits before settlement, and their larvae often experience severe predation at settlement (Doherty and Sale 1985, Planes and Lecaillon 2001, Shima 2002, Steele and Forrester 2002, Webster 2002, Doherty et al. 2004, Almany and Webster 2005, Heinlein et al. 2010). As such, differences between life stages of the same cohort may be attributable to selective predation around settlement. In particular, growth rates during the larval stage of reef fish appear to influence survival at settlement, with predators shown to select for (Booth and Hixon 1999, Booth and Beretta 2004) or against (Biro et al. 2004, Gagliano et al. 2007, Johnson and Hixon 2010) the faster growers within a cohort. Recruitment rates are notoriously variable in the marine environment (Caley et al. 1996, Bjørnstad et al. 1999, Bastrikin et al. 2014), and density may vary as a function of early life-history traits. Higher densities may be a result of better growing conditions (indicated by overall fast growth throughout the cohort) or greater retention of groups of developing larvae (indicated by similar growth pathways throughout the larval stage). In both of these scenarios, early life-history traits may be relatively homogenous and variability would be low. Alternatively, if lowered mortality during the larval stage was a result of developing in a benign environment, and all phenotypes were equally fit, variability within a cohort would be high.

Here, I evaluate variability in early life-history traits of the common triplefin. Specifically, I characterise temporal and spatial variation in traits of sampled larvae, and of postsettlement juveniles. I expect to find differences in early life-history traits over larger temporal and spatial scales (i.e. sampling dates and sites furthest apart), but not at the finer scales (i.e. day to day variation, or among sites close together). Secondly, I compare distributions of traits between life stages to evaluate preliminary evidence for selective mortality operating on larval traits around the time of settlement. Finally, I 
evaluate the relationship between larval traits and fish density for both larval and juvenile stage F. lapillum. I anticipate density to be positively correlated with early lifehistory traits (i.e., metrics of larval and juvenile quality) for both larval and juvenile stage F. lapillum.

\section{2 - Methods}

Forsterygion lapillum (the common triplefin) is a small bodied temperate reef fish, and is abundant throughout most of New Zealand's coastal shallow waters (Francis 2001, Feary and Clements 2006). Individuals hatch from eggs laid on cobble, and develop as pelagic larvae for 1-3 months (Shima and Swearer 2009a). Larvae settle to fronds of macroalgae and then move to cobble habitat as juveniles (McDermott and Shima 2006), where they remain through to adulthood. Larvae and juveniles of $F$. lapillum vary in early life-history traits (e.g. size, age, growth history and condition), and previous work (Shima and Swearer 2010, Noonburg et al. 2015, Shima et al. 2015) suggests that these traits may influence survival of individuals later in life.

Here, I integrate data from previous publications and evaluate variability in life-history traits in a more extensive set of analyses. Detailed methods of sample collection and data acquisition are provided in publications by Shima and Swearer $(2009,2016)$. Briefly, juvenile F. lapillum (hereafter, 'juveniles') were collected from artificial settlement units at approximately weekly intervals from December 2003 to March 2004. Settlement units were deployed in triplicate at each of three sites in Wellington harbour and three sites on the adjacent Wellington south coast (Fig. 2.1; see Shima and Swearer 2009 for details). Larval F. lapillum (hereafter, 'larvae') were collected with light traps over a series of four nights in January and six nights in February 2008. Light traps were deployed in triplicate at each of five sites along the eastern side of Kāpiti Island (Fig. 2.1; see Shima and Swearer 2016 for details). Both larval and juvenile sites were spatially separated from each other by $1-5 \mathrm{~km}$; larval sites (i.e. Kāpiti Island) were approximately $40 \mathrm{~km}$ north of juvenile sites (i.e. Wellington harbour and south coast). Although I evaluate and interpret variability within and among larvae and juveniles, I note that collections of the two life stages were made in different years and locations, and hence, 
comparisons between 'life-history stages' are confounded. In some of my interpretations, I make an implicit assumption that the distributions of measured lifehistory traits are robust to location and year.

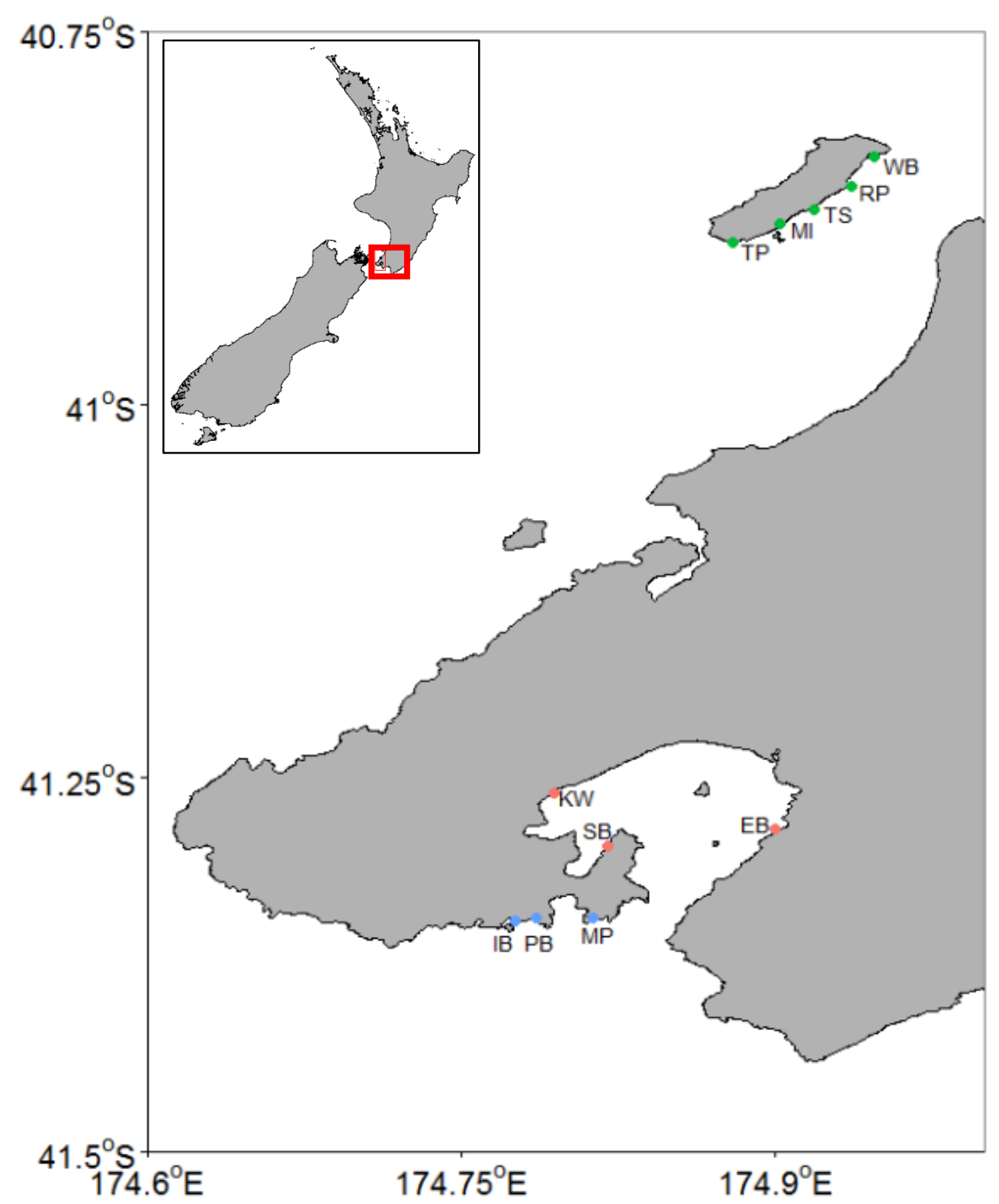

Figure 2.1 - Sampling locations for larval fish (green), harbour juveniles (red) and south coast juveniles (blue). Larval sites: WB - Waiorua Bay, RP - Rangatira Point, TS - Taepiro Stream, MI - Motungarara Island, TP - Tahiririmongo Point. Juvenile sites: KW - Kaiwharawhara, SB - Shelly Bay, EB - Eastbourne, IB - Island Bay, PB - Princess Bay, MP - Moa Point.

I collated a set of early life-history traits measured for larvae and juveniles (Shima and Swearer 2009a). Briefly, aspects of larval growth were described by three variables: 1 ) 
'size-at-hatch', 2) 'larval growth rate', and 3) 'early larval growth'. The first two variables were estimated from an exponential growth model (see Shima and Swearer 2009):

$$
L_{t}=a \cdot e^{b \cdot t}
$$

where $L_{t}$ is the otolith increment width $(\mu \mathrm{m})$ at time $t(\mathrm{~d})$ in the larval stage, $a$ is the maximum likelihood estimate of width at $t=0$ (i.e., estimated otolith 'size-at-hatch'), and $b$ is the maximum likelihood estimate of instantaneous growth rate (i.e., a measure

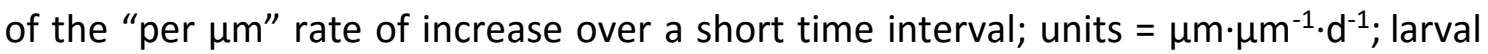
growth rate). To facilitate more direct comparisons between larvae and juveniles (that completed their larval development), larval growth rates for juveniles were estimated after standardising pelagic larval duration to a common length scale (i.e., 59 days, the maximum larval age in the larval sample).

The third aspect of larval growth, 'early larval growth' was calculated as the average width of the first five daily increments immediately after the 'hatch check'. The hatch check was identified by an abrupt increase in increment widths. More detailed methods for these measurements can be found in Shima and Swearer (2009a, 2016). These metrics of individual quality provide information on the size of the individual at hatch, growth immediately after hatch, and growth throughout the larval development measurements that have been found to influence success of both triplefins and other reef fish.

\subsection{1 - Spatio-temporal variability in early life-history traits}

I evaluated spatial and temporal variation in early life-history traits using nested ANOVA with the 'Im' function of the 'stats' package (R Core Team 2015) in R Studio v0.99.484 (RStudio Team 2015). I conducted separate analyses for larvae and juveniles, and for each of the three aspects of larval growth: 'size-at-hatch', 'larval growth rate' and 'early larval growth'. For larval F. lapillum, I nested 'site' within 'date', and for juvenile fish, I nested 'region' within 'date', and 'site' within 'region' and 'date' (because sites were split between two regions: harbour and south coast). For both larvae $(n=414)$ and juveniles ( $n=352$ ), 10 individuals per site for each collection date were used in the 
analyses, or all individuals if fewer than 10 were collected.

\subsection{2 - Differences in early life-history traits between life stages}

I explored variation in life-history traits between larvae and juveniles with separate oneway ANOVAs conducted for 'size-at-hatch', 'larval growth rate' and 'early larval growth'. I conducted one-way ANOVAs with the 'Im' function of the 'stats' package in RStudio. Any significant differences between the two groups provide circumstantial evidence for selective mortality occurring around the time of settlement, but because data were collected at different locations and times, I reiterate that this comparison is confounded.

\subsection{3 - Variability of early life-history traits as a function of density}

I evaluated larval or juvenile density as a function of early life-history traits, using general linear models. For larvae, I estimated 'density' as the total number of individuals caught in a single night at a given sight (i.e., pooled across replicate light traps deployed to each site). For juveniles, I estimated density as the total number of individuals recovered from settlement collectors at each site, standardised by the duration of collector deployment. I calculated averages (across fish collected from a given site on a given date) for i) 'size-at-hatch', ii) 'larval growth rate' and iii) 'early larval growth', and then evaluated the relationship between each trait and 'density' in separate analyses. For juveniles, I also included the interaction between each trait and region (i.e., harbour or south coast; an ANCOVA model) because these samples had a clear spatial structure.

\section{3 - Results}

Size-at-hatch of larval stage $F$. lapillum otoliths $(n=414)$ ranged from 29.7 to $60.2 \mu \mathrm{m}$ $($ mean $=40.7, \mathrm{SE}=0.2)$, and 27.6 to $75.0($ mean $=42.0, \mathrm{SE}=0.4)$ for juvenile stage $F$. lapillum. Larval growth rate of larval stage F. lapillum otoliths ranged from 0.028 to $0.066 \mu \mathrm{m} \cdot \mu \mathrm{m}^{-1} \cdot \mathrm{d}^{-1}($ mean $=0.051, \mathrm{SE}=0.001)$, and 0.017 to $0.057($ mean $=0.036, \mathrm{SE}=$ 0.001) for juvenile stage $F$. lapillum. Early larval growth rate of larval stage $F$. lapillum otoliths ranged from 1.2 to $5.0 \mu \mathrm{m} \cdot \mathrm{d}^{-1}($ mean $=2.8, \mathrm{SE}=0.1)$, and 1.0 to 3.7 (mean = 2.1, $\mathrm{SE}=0.1$ ) for juvenile stage $F$. lapillum. 


\subsection{1 - Spatio-temporal variability in early life-history traits}

For larvae, I found no significant differences in size-at-hatch among sampling dates (Fig. 2.2A; $F_{9,369}=1.886, p=0.053$ ) or sites nested within dates (Fig. 2.2B; $F_{35,369}=0.939, p=$ 0.572). I found significant differences in larval growth rate between sampling dates (Fig. 2.2C; $F_{9,369}=2.012, p=0.037$ ), but not among sites nested within dates (Fig. 2.2D; $F_{35,369}$ $=1.201, p=0.207)$. However, post-hoc analysis (Tukey's test) revealed no significant differences between sampling dates $(p>0.050)$, and no discernible patterns were found. Early larval growth differed significantly among sampling dates (Fig. 2.2E; $F_{9,369}=1.926$, $p=0.047$ ), but not among sites (Fig. 2.2F; $F_{35,369}=1.347, p=0.096$ ). As with larval growth rate, post-hoc analysis revealed no significant differences between sampling dates ( $p>$ $0.050)$, and there were no discernible patterns in early larval growth.

For juveniles, size-at-hatch differed significantly among sampling dates (Fig. 2.3A; $F_{7,309}$ $=13.892, \mathrm{p}<0.001$ ), but not between regions nested within dates (Fig. 2.3B; $\mathrm{F}_{8,309}=$ $0.677, p=0.712$ ). Size-at-hatch did differ significantly among sites nested within regions and dates (Fig. 2.3B; $F_{27,309}=2.035, p=0.002$ ). Post-hoc analysis (Tukey's test) found several pairwise differences in size-at-hatch between sampling dates (similar means denoted by shared lowercase letters on Fig. 2.3A), and size-at-hatch generally increased during the sampling season. However, post-hoc analysis found no significant differences in size-at-hatch between sites nested within regions and dates $(p>0.050)$. Larval growth rate differed significantly among sampling dates (Fig. 2.3C; $F_{7,309}=7.150, p<0.001$ ), but not between regions nested within dates (Fig. 2.3D; $F_{8,309}=1.292, p=0.247$ ). I also found significant differences among sites nested within regions and dates (Fig. 2.3D; F 27,309 = $1.677, p=0.021$ ). Post-hoc analysis found several pairwise differences in larval growth rate between sampling dates (similar means denoted by shared lowercase letters on Fig. 2.3C), and larval growth rate was greatest in mid-summer compared to either the start or end of the sampling season. Post-hoc analysis found no significant differences in larval growth rate between harbour sites nested within regions and dates, but larval growth rates of fish collected on the south coast were significantly lower in Island Bay compared to Princess Bay $(p=0.035)$. Early larval growth differed significantly among 
sampling dates (Fig. 2.3E; $F_{7,309}=11.734, p<0.001$ ), between regions nested within dates (Fig. 2.3F; $F_{8,309}=3.669, p<0.001$ ), and among sites nested within regions and dates (Fig. 2.3F; $F_{27,309}=1.874, p=0.006$ ). Post-hoc analysis found several pairwise differences in early larval growth (similar means denoted by shared lowercase letters on Fig. 2.3E), and early larval growth generally increased during the sampling season. Juveniles collected from harbour sites grew more quickly during the early larval period compared to those from the adjacent south coast. However, post-hoc analysis did not find any significant differences in early larval growth among sites nested in regions and dates. 

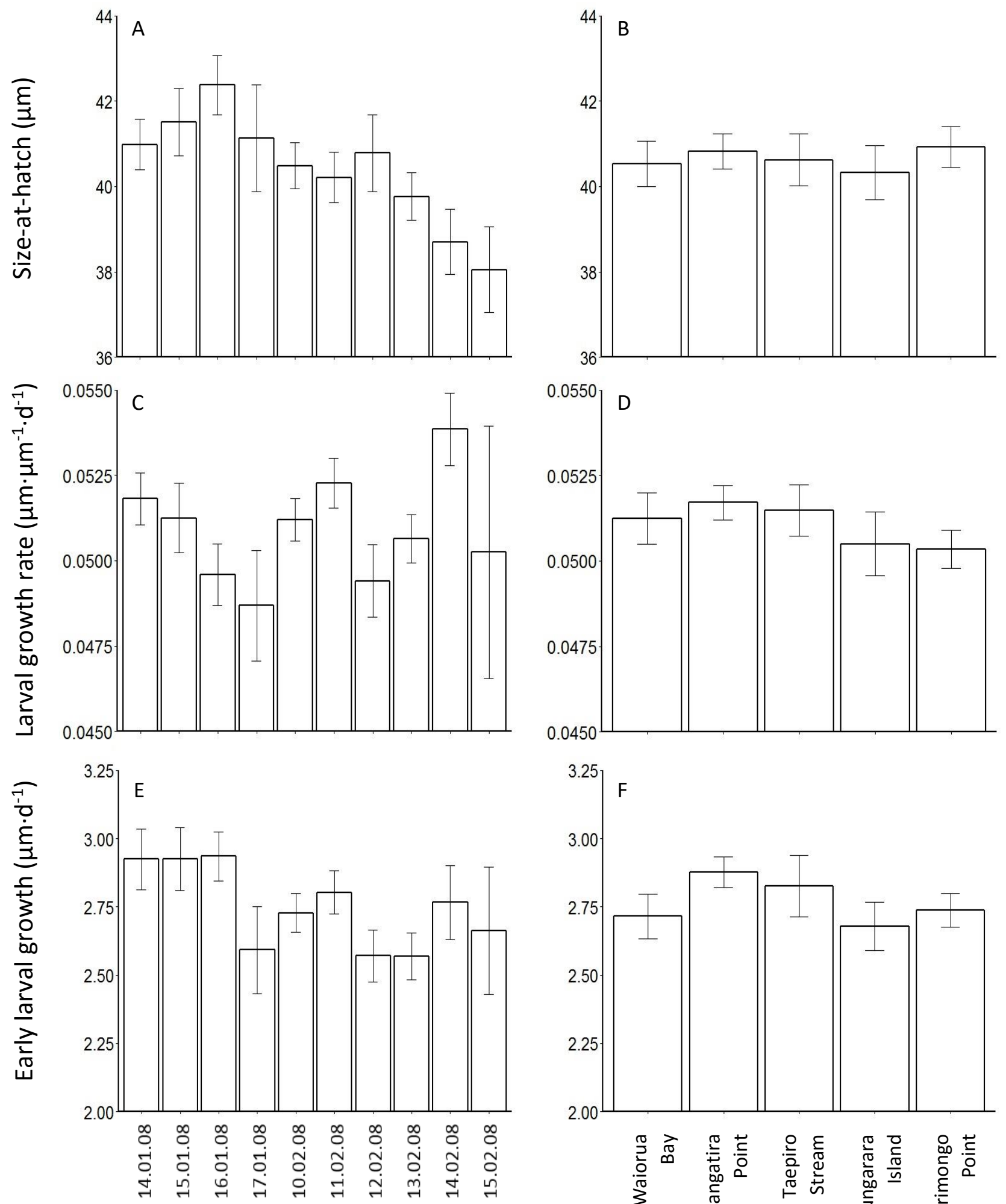

Date

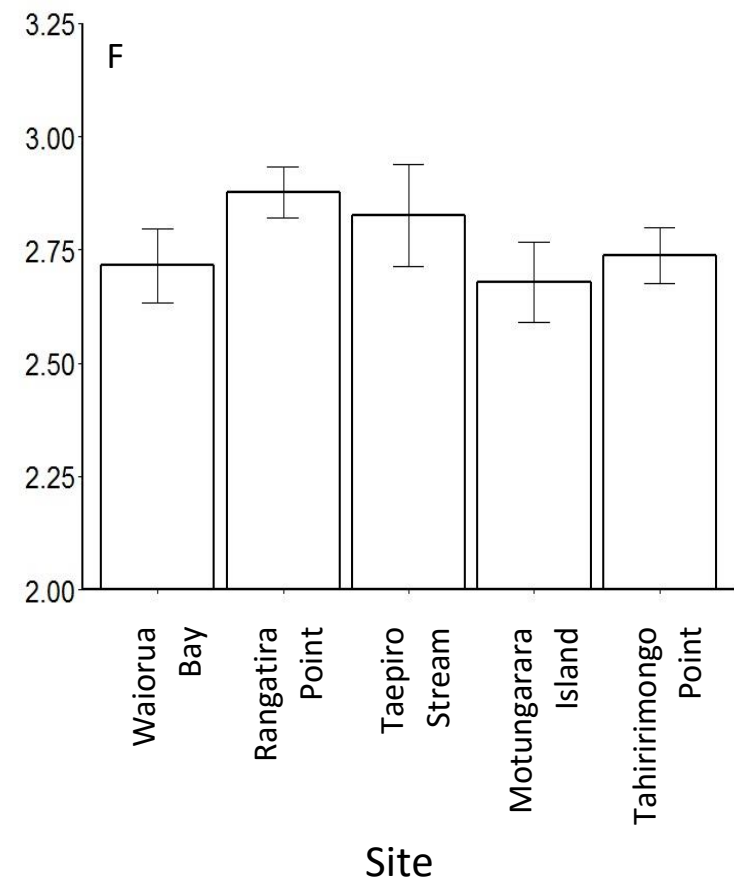

Figure 2.2 - Temporal (left column panels) and spatial (right column panels) variation in early life-history traits. Given are average \pm SE (error bars) (A, B) size-at-hatch, (C, D) larval growth rate and $(\mathrm{E}, \mathrm{F})$ early larval growth in larval $F$. lapillum. 

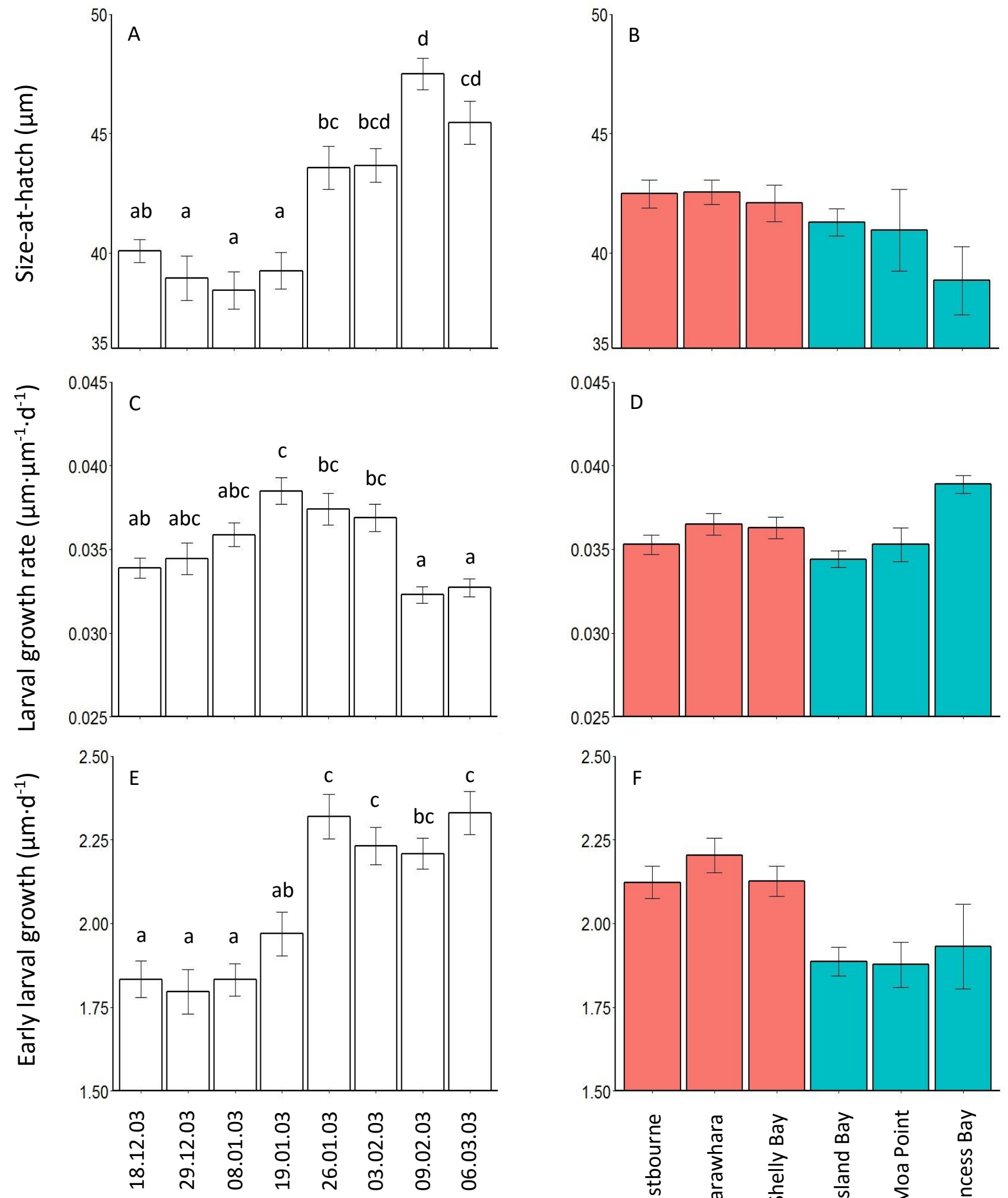

\section{Date}

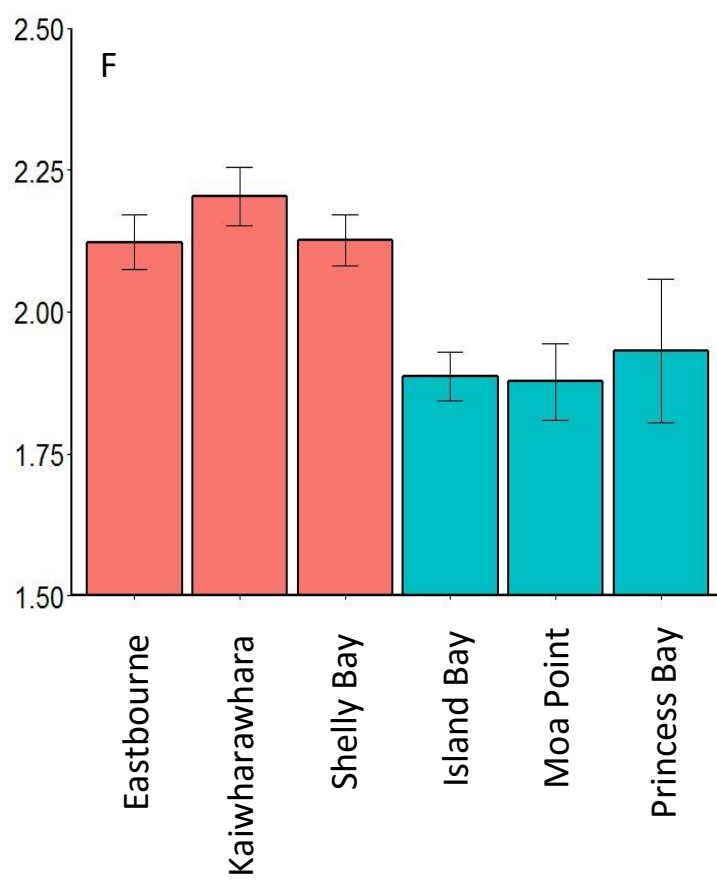

Site

Figure 2.3 - Temporal (left column panels) and spatial (right column panels) variation in early life-history traits. Given are average \pm SE (error bars) (A, B) size-at-hatch, (C, D) larval growth rate and $(E, F)$ early larval growth in juvenile $F$. lapillum. Lowercase letters (left panels only) denote groups of similar means as determined by Tukey's test. Regions (right panels only) are represented by colours: red = harbour, blue = south coast. 


\subsection{2 - Differences in early life-history traits between life stages}

All measured early life-history traits differed significantly between larvae and juveniles (Fig. 2.4). Juveniles had otoliths that were significantly larger at hatch than larvae (Fig. $\left.2.4 \mathrm{~A} ; \mathrm{F}_{1,764}=9.670, \mathrm{p}<0.001\right)$, and also grew more slowly immediately after hatching (Fig. 2.4B; $F_{1,764}=257.100, p<0.001$ ). Juveniles also had slower larval growth rate (Fig. 2.4C; $\left.F_{1,764}=1208.100, p<0.001\right)$.

\subsection{3 - Variability of early life-history traits as a function of density}

For larvae, density did not differ significantly with either size-at-hatch $\left(F_{1,43}=2.829, p=\right.$ $0.100)$, or larval growth rate $\left(F_{1,43}=0.981, p=0.328\right)$. Density was positively correlated with early larval growth (Fig. 2.5; $F_{1,43}=5.408, p=0.025$ ), indicating that individuals that grew quickly immediately after hatch were collected in higher densities. However, the relationship between early larval growth and density was weak $(r=0.091)$.

For juveniles, I found no significant effect of size-at-hatch on juvenile density $\left(F_{1,39}=\right.$ 1.495, $p=0.229$ ), and this pattern was consistent between regions (interaction term: $\left.F_{1,39}=1.021, p=0.318\right)$. In a reduced model without the interaction term, density still did not vary significantly with size-at-hatch $\left(F_{1,40}=0.583, p=0.450\right)$. Density also did not differ significantly with larval growth rate $\left(F_{1,39}=3.149, p=0.084\right)$ and this pattern was again consistent between regions (interaction term: $F_{1,39}=3.909, p=0.055$ ). In a reduced model without the interaction term, density did not differ significantly with larval growth rate $\left(F_{1,40}=0.384, p=0.539\right)$. Density also did not vary significantly with early larval growth $\left(F_{1,39}=0.265, p=0.610\right)$, and this pattern was consistent between regions (interaction term: $F_{1,39}=3.000, p=0.091$ ). In a reduced model without the interaction term, density still did not differ significantly with early larval growth $\left(\mathrm{F}_{1,40}=\right.$ $0.552, p=0.462)$. In all three analyses, region was not a significant main effect in the full model $(p>0.050)$, but was in the reduced model $(p<0.050)$; juvenile density was significantly higher in the harbour than on the adjacent south coast. 

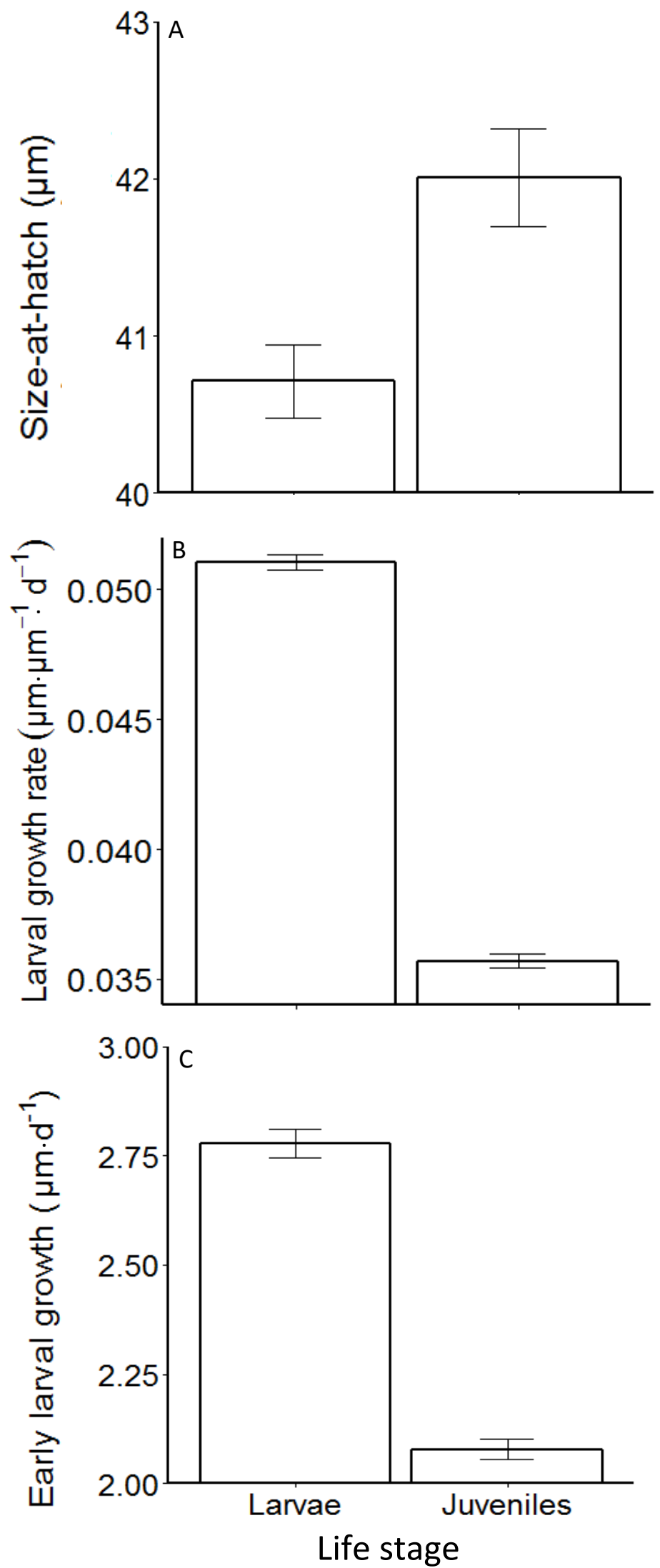

Figure 2.4 - Variation in early life-history traits between larvae $(n=414)$ and juveniles $(n=352)$ of $F$. lapillum. Given are average \pm SE (error bars) (A) sizeat-hatch, (B) larval growth rate, and (C) early larval growth. 


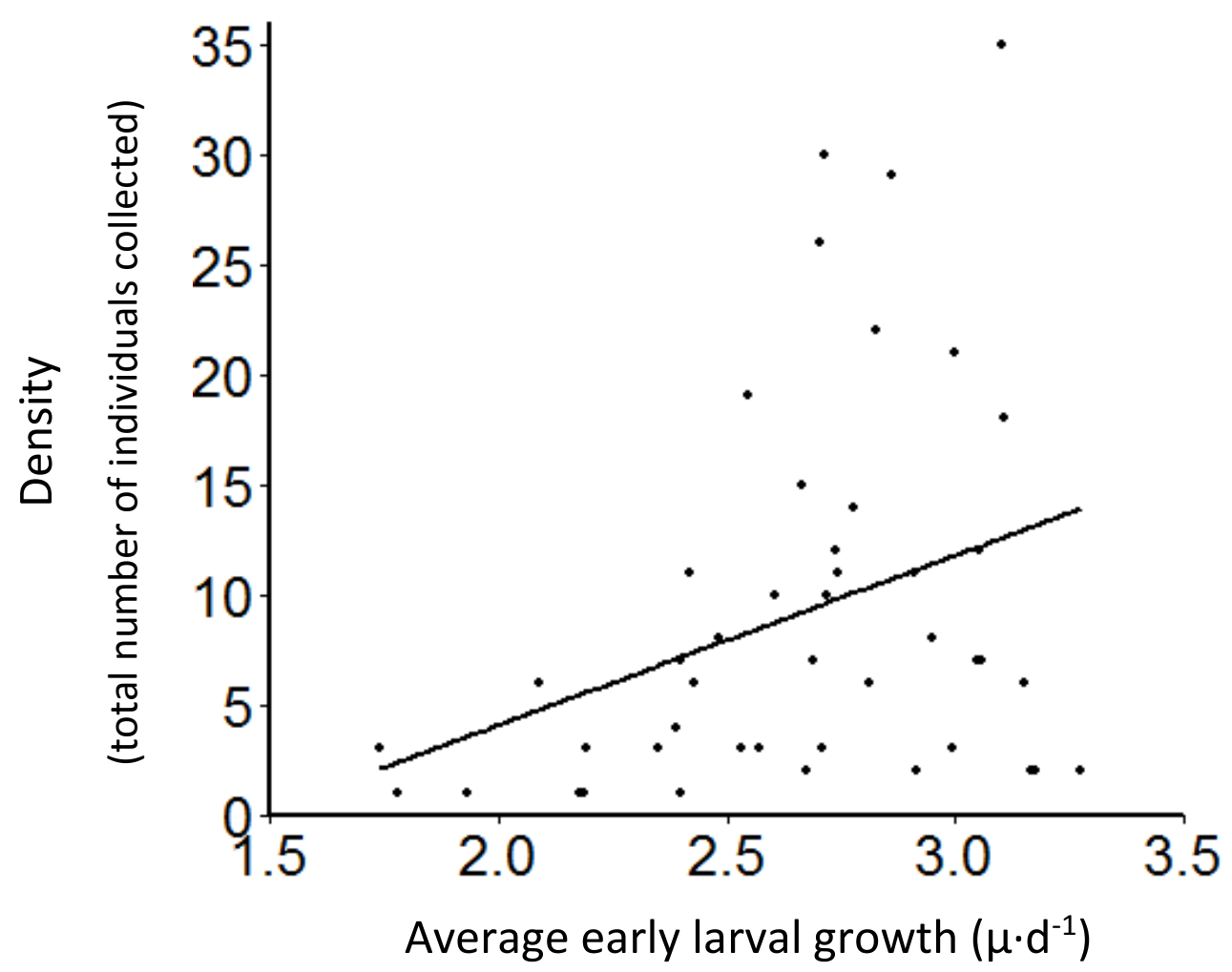

Figure 2.5 - Density varies as a function of average early larval growth for larval F. lapillium. Density is expressed as the total number of individuals collected for a given site and date. Fitted line represent results of linear model.

\section{4 - Discussion}

\subsection{1 - Variability in early life-history traits}

As predicted, differences in early life-history traits were found at larger temporal and spatial scales, but not at finer scales. Although early life-history traits varied through time for both larvae and juveniles, observed patterns of variation were markedly different between the two life stages. Larvae showed little evidence of interpretable variation whereas juveniles showed clear seasonal patterns. These differences in patterns may be due to life stages, years or locations, but could also be a result of the differences in sampling period length. Although larvae were sampled at a much finer scale (i.e., nightly sampling over two weeks), juveniles were sampled over a longer time period (i.e., roughly weekly intervals over four months). This helped resolve seasonal 
patterns that were not evident in sampled larvae, but may have been observed if a similar sampling method was used. For juveniles, larval growth rate was greatest at the height of summer, which is likely a result of increased water temperature during this time. Size-at-hatch and early larval growth of juveniles increased towards the end of summer. Both of these early life-history traits can be influenced by yolk provisioning (e.g., higher yolk quality may produce larger and faster growing offspring), and this may represent a bet-hedging strategy by mothers as the season progresses (Maddams and McCormick 2012). Alternatively, this may be an artefact of the shorter development window, with only larger and faster growing individuals reaching settlement competency at the end of the season.

Larvae exhibited no spatial differences in early life-history traits, and although there were significant among-site differences in both measures of growth for juveniles, only early larval growth differed over the larger regional scale. Juveniles collected on the south coast had slower early larval growth than those in the harbour, and this difference may be due to environmental differences between the two regions; the harbour is thought to be a more beneficial growing environment than the south coast (e.g. warmer waters, greater food availability). Lower nutrient availability and prey abundance on the south coast is thought to limit benthic marine communities (Gardner 2000), and could also influence fish growth during the early larval stage.

Contrary to my expectations, density was not positively correlated with all early lifehistory traits in either ontogenetic stage. Only early larval growth was positively correlated with density for sampled larvae, and fast growth has been linked to increased recruitment in other systems (Bergenius et al. 2002, Wilson and Meekan 2002, Jenkins and King 2006, Murphy et al. 2014). Fast growth is thought to be indicative of favourable growing conditions during the larval development period. If early larval growth can be used as a proxy for rate of development, then fast growth (and quicker development of swimming ability) could allow individuals to stay onshore, increasing the likelihood of settlement. Groups of pre-competent settlers can be seen schooling near the reef along the south coast during summer months (P Caie pers. obs.), and it may be that these 
individuals are those with faster early larval growth. Unlike larvae, juveniles exhibited no significant relationships between early life-history traits and density, and this difference may be attributable to differences in sampling years (i.e. 2003/2004 versus 2008) or locations (i.e. Wellington versus Kāpiti). Spatial (Hamer and Jenkins 2004, Johnson and Hixon 2010) or temporal (Campana 1996, Robert et al. 2007, Rankin and Sponaugle 2011a, Murphy et al. 2014) variability in relationships between early lifehistory traits and density have been found in long-term studies in other fish species. Alternatively, any relationship between early-life history traits and post-settlement juvenile density may be masked if selective mortality on these traits occurs around settlement e.g. (Murphy et al. 2014).

\subsection{2 - Potential for selective mortality on early life-history traits}

Assuming that my samples of larvae and juveniles (made in different locations and times) provide robust and comparable estimates of early life-history traits for each stage, then differences between the two age groups may be indicative of selective mortality that occurs around the time of settlement. Under this assumption, successful individuals (i.e., that survive to become juveniles) were those that developed more slowly during the larval period. Selection for the slower growing individuals within a cohort contradicts the growth-mortality hypothesis (Anderson 1988, Sogard 1997), but has been documented in many other studies (Billerbeck et al. 2001, Lankford et al. 2001, Biro et al. 2003b, Biro et al. 2004, Robert et al. 2007, Sponaugle et al. 2011). Faster growth can be detrimental to individuals if food supply does not meet metabolic demand, as individuals may starve if unable to alter energetic requirements.

If selective removal of faster growing individuals is indeed occurring, then the actions of predators around the time of settlement may be the cause, (e.g., Steele and Forrester 2002). Predation is an important source of mortality during settlement for many reef fish, and selection against faster growing settlers may be mediated by the size, condition or behaviour of an individual. Faster larval growth may necessitate increased foraging after settlement (e.g. due to increased metabolic demand); searching for food in the presence of predators instead of using refuge could increase encounter rates with 
predators, and elevate predation risk (Billerbeck et al. 2001, Lankford et al. 2001, Biro et al. 2004, Biro and Post 2008, Johnson and Hixon 2010). Greater food intake can also increase the size and/or condition of an individual, and predators may selectively remove these individuals if they are perceived as more favourable prey items (Pepin et al. 1992, Lundvall et al. 1999, Hoey and McCormick 2004, Holmes and McCormick 2006, 2009).

\subsection{3 - Conclusions}

These results indicate that young F. lapillum vary considerably in their early life-history traits. This variation provides an opportunity for selective mortality to occur. Larvae varied most in their early life-history traits through time, whereas juveniles were variable through time and space. This may suggest that the quality of larvae and juveniles varies over these scales, which could result in differences in post-settlement success both spatially and temporally. Selective mortality operating on faster larval development around the transition from a pelagic to benthic environment could explain differences between larval and juvenile cohorts. Though the evidence is only circumstantial, these observations form the basis for a set of hypotheses that I evaluate in the following chapter. 


\section{Chapter 3 - Predator-induced selective mortality in the early life stages of a temperate reef fish}

\section{1 - Introduction}

Selective mortality is a crucial regulator of phenotypic variation (Hoekstra et al. 2001, Kingsolver et al. 2001, Hereford et al. 2004, Kingsolver and Pfennig 2007, Siepielski et al. 2009), and is important for driving patterns at ecological (Davenport et al. 2014, Johnson et al. 2014, Bijleveld et al. 2015) and ultimately evolutionary scales (Day et al. 2002, Dmitriew 2011, Taborsky et al. 2012, Svardal et al. 2014). As the quality of an individual is often determined by its phenotype, individual survival and reproduction will co-vary with phenotypic traits (Ferguson and Fox 1984, Warner and Andrews 2002, Le Galliard et al. 2004). Marine organisms are well studied in this regard, as many phenotypic traits are highly variable and selective mortality is often strong (Sogard 1997, Perez and Munch 2010, Johnson et al. 2012, Johnson et al. 2014, Rankin and Sponaugle 2014). Selection on body size and growth rates in early life stages may determine year-class strength, as these traits have been correlated with recruitment success for various fishes (Miller et al. 1988, Jenkins and King 2006, Hamilton 2008, Hamilton et al. 2008, Shima and Swearer 2009b, Swearer and Shima 2010). The quality of recruiting individuals may influence population stability and equilibrium (Booth and Beretta 2004, Cowen and Sponaugle 2009, Shima and Swearer 2009a, Johnson et al. 2014, Noonburg et al. 2015, Shima and Swearer 2016), and as such, selective mortality may play an important role in controlling demographic processes within metapopulations. At an evolutionary scale, selective mortality can determine life-history traits such as growth and development rates (Reznick 1982, Reznick et al. 1990, Abrams and Rowe 1996, Takatsu and Kishida 2015) - this has been documented in natural predator-prey interactions (Reznick 1982, Davenport et al. 2014) as well as in fisheries where exploitation of stocks has resulted in changes in size- and age-at-maturation (Law 2000, Conover and Munch 2002, Gårdmark et al. 2003, Olsen et al. 2009, Audzijonyte et al. 2012, Bodin et al. 2012). 
Size- and growth-selective mortality is well documented for many marine organisms (Paine 1976, Bijleveld et al. 2015), particularly fishes (Good et al. 2001, Shima and Findlay 2002, Munch and Conover 2003, Biro et al. 2005, Gagliano et al. 2007). Evidence suggests that these traits may be important in determining survival of individuals, especially in early life stages such as larvae and juveniles (Hare and Cowen 1997, Sogard 1997, Booth and Hixon 1999, Good et al. 2001, Holmes and McCormick 2006, Dibattista et al. 2007, Holmes and McCormick 2009). For many decades, is was assumed that larger fish were less susceptible to size-selective mortality, and faster growing individuals were cumulatively less vulnerable, as they could more quickly attain a larger size than their slower growing peers (reviewed in Anderson 1988, Leggett and Deblois 1994, Sogard 1997). Although some studies have found that larger or faster growing individuals experience increased survival (Rice et al. 1993, Hare and Cowen 1997), support for 'bigger-is-better' and 'faster-is-better' is equivocal at best (Hendry et al. 2003, Munch and Conover 2003, Holmes and McCormick 2006, Dibattista et al. 2007, Gagliano et al. 2007, Carlson et al. 2008, Rankin and Sponaugle 2011a).

Predators represent one of the largest sources of mortality for young fish, and are capable of significantly reducing abundance of settling larvae and juveniles in reef systems (Doherty and Sale 1985, Carr et al. 2002, Shima 2002, Webster 2002, Doherty et al. 2004, Almany and Webster 2005). As such, predation has the potential to be a strong source of selective mortality. Size-selective predation may favour larger individuals if predators are gape-limited (Mattingly and Butler 1994, Persson et al. 1996, Nilsson and Bronmark 2000, Scharf et al. 2000), or if access to refuges from predators is monopolised by the biggest individuals (Lundvall et al. 1999, Holbrook and Schmitt 2002).

As body growth in fish and other marine organisms is often determined by environment and resource availability (Houde 1989, Houde and Zastrow 1993, Meekan et al. 2003, Grorud-Colvert and Sponaugle 2011, Rankin and Sponaugle 2011a), increased foraging can result in faster growth. While faster growth may allow individuals to reach larger sizes sooner, fast growth can also be detrimental to an individual's success (Billerbeck et al. 2001, Lankford et al. 2001, Dmitriew 2011). For example, if individuals are feeding 
in the presence of predators instead of using refuge, selective predation may remove faster growing and larger individuals (Biro et al. 2004, Gagliano et al. 2007, Johnson and Hixon 2010). Organisms must weigh up costs and benefits of foraging, which will be determined by factors including resource availability, environmental risk, energetic demands and recent feeding history (Biro et al. 2003b, c, Lonnstedt and McCormick 2011, Lonnstedt et al. 2012, Hammerschlag et al. 2015).

Marine fish are also often subject to carry-over effects, i.e., larval experiences or traits that influence future success (Pechenik et al. 1998, Bergenius et al. 2002, Shima and Findlay 2002, Hoey and McCormick 2004, Grorud-Colvert and Sponaugle 2011). Selective mortality may be acting on present morphology or behaviour, but these may have been determined by the early life-history of an individual (Wilson and Osenberg 2002, Sponaugle and Pinkard 2004a, Gagliano et al. 2007, Lonnstedt and McCormick 2011). Larval growth has been shown to influence post-settlement survival for reef fish. In some instances, fast growth throughout the larval period results in elevated survival for juveniles (Vigliola and Meekan 2002, Sponaugle and Grorud-Colvert 2006, Vigliola et al. 2007, Shima and Swearer 2010), but other studies have found fast growth during particular segments of the larval stage, e.g. shortly after hatching (Vigliola and Meekan 2002, Macpherson and Raventos 2005, Raventos and Macpherson 2005, D'Alessandro et al. 2013), or before settlement (Hoey and McCormick 2004, McCormick and Hoey 2004, Hamilton 2008, Hamilton et al. 2008, Lonnstedt and McCormick 2011) to be more influential on future success.

Field studies often rely on comparisons of traits within a cohort over time to identify shifts in phenotypic distributions (Vigliola et al. 2007, Sponaugle et al. 2011), but observed differences may not always be attributable to a single selection event, e.g. predation at settlement. Multiple selection events may occur between sampling times, each with their own selection strengths and directions (Schluter et al. 1991, Hoekstra et al. 2001, Gagliano et al. 2007, Siepielski et al. 2009, Johnson and Hixon 2010). This is likely to be the case around metamorphosis and settlement of reef organisms, when larvae leave the pelagic environment and move to the benthic adult habitat (Dahlgren and Eggleston 2000, McDermott and Shima 2006, Lecchini et al. 2007, Snover 2008) - 
sampling infrequently during this time frame may not accurately capture the strength and direction of selective mortality.

Recruitment can be highly variable (Caley et al. 1996, Sponaugle et al. 2002), and young fish are likely to encounter selective events at different densities. Selection processes have the capacity to change with conspecific density (e.g., Vigliola et al. 2007, Samhouri et al. 2009, Johnson and Hixon 2010, Hansen and Beauchamp 2014), although the majority of studies do not consider the role of density in selective mortality at settlement for reef fish. Where predation rates are influenced by prey density, selective predation is also likely to change with density (Samhouri et al. 2009, Wormald et al. 2013, Hansen and Beauchamp 2014, Murphy et al. 2014). When predation is driven by encounter rates, certain phenotypes may be more likely to be encountered at lower densities and selective predation will be stronger. This could occur if the density of prey also influences other components of prey vulnerability, such as refuge use (Beukers and Jones 1998, Holbrook and Schmitt 2002, Forrester and Steele 2004, Hixon and Jones 2005, Johnson 2006, 2007, Hixon et al. 2012) or growth rates (Booth 1995, Tupper and Boutilier 1995, Lorenzen and Enberg 2002, Gårdmark et al. 2006, Johnson 2008, Samhouri et al. 2009).

The aim of this chapter was to determine if size- or growth-selective predation occurs for young Forsterygion lapillum, and if selection patterns change with ontogeny or conspecific density. To address these questions, I exposed young triplefins at two early life stages (larval and juvenile stage) to natural predators, and compared the size and growth history traits of consumed fish to unconsumed fish. Predation trials were run at three different densities (low, mid and high) to investigate whether patterns of selection change with increasing prey density. I use these experiments to determine if larger or faster growing individuals have increased relative fitness as predicted by the 'bigger-isbetter' and 'faster-is-better' hypotheses. As many studies find alternating patterns of selection through ontogeny, I also expect to find differences in selection on larval and juvenile stage F. lapillum. Lastly, as prey density is known to influence predation rates, I expect patterns of selection to differ with density of F. lapillum. 


\section{2 - Methods}

\subsection{1 - Study species}

Forsterygion lapillum is a small bodied temperate reef fish, and is abundant throughout most of New Zealand's coastal shallow waters (Francis 2001, Feary and Clements 2006). Individuals hatch from eggs laid on cobbles, and develop as pelagic larvae for 1-3 months (Shima and Swearer 2009a). Larvae settle to fronds of macroalgae and then move to cobble habitat as juveniles (McDermott and Shima 2006), where they remain through adulthood. Larval and juvenile stages of $F$. lapillum vary in early life-history traits (e.g., size, age, growth history, condition), and previous work (Shima and Swearer 2010, Noonburg et al. 2015, Shima et al. 2015) has shown that these traits can influence survival later in life. Recruitment of larval and juvenile triplefins is also variable (Swearer and Shima 2010, Shima and Swearer 2016), so young triplefins potentially experience selection over a range of densities.

\subsection{2 - Fish collections}

I collected larval F. lapillum from Shelly Bay $\left(41^{\circ} 29^{\prime} 71^{\prime \prime}\right.$ S, $\left.174^{\circ} 81^{\prime} 96^{\prime \prime} E\right)$ and Kau Bay (41⒉ $28^{\prime} 73^{\prime \prime}$ S, 174 $\left.82^{\prime} 94^{\prime \prime} \mathrm{E}\right)$ in Wellington harbour between December 2014 and January 2015, using light traps (described in Shima and Swearer 2016). I collected recently settled F. lapillum from the same sites in February and March 2015 using artificial collectors that simulated algal canopies (described in Shima and Swearer 2009a). Collected individuals were returned to Victoria University's Coastal Ecology Laboratory (VUCEL) and maintained in covered glass aquaria for $\sim 24 \mathrm{~h}$ prior to predation trials. Young F. lapillum are preyed upon by a related species of triplefin (F. varium, the variable triplefin; Mensink and Shima 2014). I used F. varium as the model predator in my experiments, and collected these individuals from Princess Bay, Wellington south coast $\left(41^{\circ} 34^{\prime} 68^{\prime \prime} S, 174^{\circ} 79^{\prime} 04^{\prime \prime} E\right)$ with hand-nets and aided by SCUBA. Predators were maintained in glass aquaria at VUCEL for at least one week prior to predation experiments, on a diet of crushed mussels. Predators were not fed in the 24 hours prior to predation trials. 


\subsection{3 - Mesocosms to evaluate selective predation}

I constructed four mesocosms to test for selective predation of $F$. lapillum as a function of size and/or growth histories. Mesocosms consisted of shaded 1000L outdoor tanks filled with a $\sim 3 \mathrm{~cm}$ layer of cobble substrate and a single stipe of $C$. retroflexa to provide standardised structural complexity for larval and juvenile stages of $F$. lapillum. Mesocosms were stocked with two predator individuals (adult F. varium), one of three densities of prey (F. lapillum), and continuously supplied with a constant flow of sea water. I evaluated selective predation on larval stages and juvenile stages of $F$. lapillum in separate experiments. Density treatments for larval stages were 10, 20, or 30 fish per tank; density treatments for juveniles were 5,10 , or 15 individuals per tank (these different treatment levels were based upon typical densities found in the two types of collectors; Morton and Shima 2013, Shima and Swearer 2016). I replicated treatments through time ( $\mathrm{n}=2$ trials); and in addition, I doubled the replication for the lowest density treatments within each time to increase statistical power.

For each experiment, I measured the total length ( $T L$ ) of all F. lapillum to the nearest $0.1 \mathrm{~mm}$, and haphazardly assigned them to density treatments to achieve similar sizedistributions across tanks. F. varium were similarly measured and haphazardly assigned to tanks to achieve an even size distribution across tanks. F. lapillum (prey) were introduced first and allowed to acclimate for at least 1 hour prior to the addition of $F$. varium (predators). Predators were added at dusk, and tanks were left undisturbed for $24 \mathrm{~h}$ (i.e., the duration of a trial). At the conclusion of each trial, all predators and surviving prey were removed and re-measured (facilitating an estimate of the size distribution of survivors and of consumed fish; i.e., missing fish were assumed to be consumed). All fish were then euthanized in an ice-slurry, and preserved (predators were frozen for future dissection; prey were preserved in ethanol; facilitating estimates of otolith-based traits, described below).

Selection on phenotypes can act on the mean value of a trait (i.e., linear selection), or change the variance of the trait (i.e., non-linear selection). To evaluate the strength and direction of the linear selection differential on size $(S)$, I evaluated a multiple regression 
analysis of relative fitness on standardised size, using methods outlined in Lande and Arnold (Lande and Arnold 1983). Size was standardised by computing the z-score for each observation, and each mesocosm (and for each trial) was standardised separately. I modelled relative fitness as a function of size ( $T L)$, the interaction of size and density treatment (using density as a categorical variable), and I included 'block' as a random effect to account for the two separate trials. To estimate the non-linear selection differential $(C)$, I evaluated the same model using the squared term of standardised size. For both selection differentials, I evaluated a full model with the interaction term, and where this was found to be non-significant, I evaluated a reduced model consisting of only the main effects. I used the 'Imer' function of the 'Ime4' package (Bates et al. 2015) in R Studio v0.99.484 to run both linear and non-linear selection models.

\subsection{4 - Otolith analyses to evaluate selection based on growth histories}

Sagittal otoliths ('ear stones') grow in daily increments (Campana and Neilson 1985) and can be used to determine age and growth histories of F. lapillum (Shima and Swearer 2009a, 2016). I extracted sagittal otoliths from all fish used in my predation experiments (e.g., from the sample of surviving F. lapillum, or recovered from predator guts; Fig. 3.1) to infer the age and growth histories of survivors and of consumed individuals. I had a high recovery rate of otoliths from the predator guts; only five larval pairs and one juvenile pair could not be recovered.

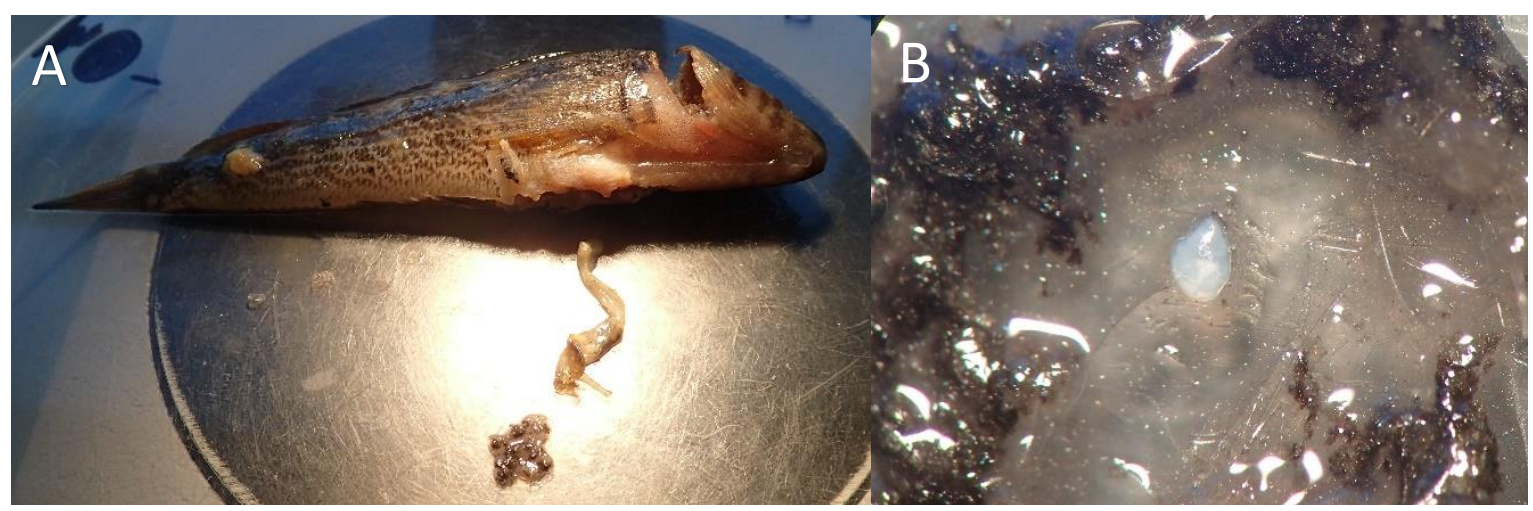

Figure 3.1: A - Forsterygion varium predator dissected to recover otoliths of consumed prey ( $F$. lapillum) from gut contents. B - A sagittal otolith from F. lapillum isolated from gut contents of predator (10x magnification).

Otoliths extracted from predator guts were photographed and sagittal otolith pairs (i.e., left and right) were matched based on their size and shape to ensure that only a single 
otolith from each fish was evaluated. To expose the daily growth increments, otoliths were either soaked in emersion oil for several weeks or polished along the sagittal plane with diamond lapping film to expose the post-rostral growth axis. Otoliths were photographed at 400x (or 200x for larger samples) using a digital SLR camera (EOS 70D Canon) coupled to a Leica compound microscope.

I used the Otolith M app in Image-Pro Premier v9.1 (MediaCybernetics, Bethesda, Maryland, USA) to count and measure the daily growth increments. Following the general approach of Shima and Swearer (2009a), I estimated pelagic larval duration as the number of increments between a conspicuous 'hatch check' and 'settlement check' (for larvae captured in light traps, this was simply the number of increments from hatch check to the edge of the otolith). F. lapillum otolith increments grow exponentially during the larval period (Shima and Swearer 2009), and I fit an exponential growth model to larval otolith growth chronologies:

$$
L_{t}=a \cdot e^{b \cdot t}
$$

where $L_{t}$ is the otolith increment width $(\mu \mathrm{m})$ at time $t(\mathrm{~d})$ in the larval stage, $a$ is the maximum likelihood estimate of width at $t=0$, and $b$ is the maximum likelihood estimate of instantaneous growth rate (i.e., a measure of the "per $\mu \mathrm{m}$ " rate of increase over a short time interval; units $\left.=\mu \mathrm{m} \cdot \mu \mathrm{m}^{-1} \cdot \mathrm{d}^{-1}\right)$. I estimated $a$ and $b$ using the 'nlsLM' function of the 'minpack.Im' package (Elzhov et al. 2013) in R Studio v0.99.484 (RStudio Team 2015). For juveniles, I also estimated their average late larval growth rate as growth immediately before settlement has been found to influence post-settlement survivorship in F. lapillum (Smith and Shima 2011). I estimated average late larval growth as the average width of the five increments immediately before the settlement check. As my results from Chapter 2 identified similar patterns of ontogenetic differences in larval growth rate and early larval growth, I choose to exclude early larval growth from the analyses in this chapter.

I calculated selection gradients to provide analogous information to selection differentials (as above) while allowing for correlational selection between covarying traits. To evaluate the strength and direction of linear selection gradients $(\beta)$ on growth, 
I ran a multiple regression analysis of relative fitness on standardised variables, using methods outlined in Lande and Arnold (1983). Growth variables were standardised by computing the z-score for each observation, and each mesocosm (and in each trial) was standardised separately. Again, I modelled relative fitness for larvae (experiment 1) as a function of larval growth rate $(b)$, larval age (PLD), the interaction terms between each growth trait and density, and 'block' as a random effect. For juveniles (experiment 2) my model also included late larval growth and the interaction term between late larval growth and density as predictors. To estimate non-linear selection gradients $(\psi), \mathrm{I}$ ran similar multiple regression models using the squared term of standardised traits, and interaction terms for all variables. I sequentially removed non-significant, higher-order interaction terms to determine a reduced model. I used the 'Imer' function of the 'Ime4' package in R Studio v0.99.484 to run both linear and non-linear selection models.

\section{3 - Results}

Larval stage $F$. lapillum $(\mathrm{n}=140)$ ranged in size from 23.2 to $30.7 \mathrm{~mm}$ (mean $=26.5, \mathrm{SE}=$ 1.3). Juvenile stage F. lapillum $(n=70)$ ranged from 22.0 to 30.7 (mean $=25.7, S E=1.9$ ). Larval age ranged from 32 to 69 days (mean $=47.1, \mathrm{SE}=5.6$ ) for larval stage $F$. lapillum, and 37 to 59 days (mean $=45.5, \mathrm{SE}=4.4$ ) for juvenile stage $F$. lapillum. Although larval and juvenile triplefins were similar in age and size for this sample, the two stages were morphologically distinct; all larvae were unpigmented (Fig. 1.1A) and all juveniles (Fig. 1.1B) had colouration suggesting they were at qualitatively different stages of development. Larval growth rate $(b)$ for larval F. lapillum otoliths ranged from 0.033 to $0.059 \mu \mathrm{m} \cdot \mu \mathrm{m}^{-1} \cdot \mathrm{d}^{-1}(\operatorname{mean}=0.046, \mathrm{SE}=0.005)$, and 0.038 to $0.057 \mu \mathrm{m} \cdot \mu \mathrm{m}^{-1} \cdot \mathrm{d}^{-1}($ mean $=$ $0.046, \mathrm{SE}=0.004)$ for juvenile stage $F$. lapillum. For juvenile stage $F$. lapillum, late larval otolith growth ranged from 5.3 to $12.9 \mu \mathrm{m} \cdot \mathrm{d}^{-1}$ (mean = 9.0, SE = 1.6).

\subsection{1 - Selective predation as a function of size and density}

For larval stage F. lapillum, linear selection on size was strong and negative (Fig. 3.2A; $\left.S_{T L}=-0.618, S E=0.059 ; F_{1,135}=108.959, p<0.001\right)$, indicating larger larvae had reduced fitness. Patterns of linear selection were also consistent across densities (interaction term: $F_{2,135}=1.932, p=0.149$ ). I evaluated a reduced model using only size as a main 
effect, and found qualitatively similar results to the full model. Linear selection on size in the reduced model was strong and negative $\left(S_{T L}=-0.699, S E=0.035 ; F_{1,137}=312.502\right.$, $p<0.001)$. I also found negative but weak non-linear selection on size $\left(C_{T L}=-0.129\right.$, SE $\left.=0.060 ; F_{1,135}=4.613, p=0.034\right)$, indicating a small reduction in variance of size after adjusting for linear selection. Again, the interaction between size and density in the non-linear selection model was non-significant $\left(F_{2,135}=0.403, p=0.669\right)$, so I evaluated a reduced model without the interaction term. Results from the reduced model were qualitatively similar to those from the full model; non-linear selection on larval size was negative but weak $\left(C_{T L}=-0.157, \mathrm{SE}=0.051 ; F_{1,137}=9.6104, \mathrm{p}=0.002\right)$.

For juvenile stage $F$. lapillum, linear selection on size was non-significant $\left(S_{T L}=0.037, \mathrm{SE}\right.$ $\left.=0.137 ; F_{1,65}=0.075, p=0.786\right)$, but patterns of linear selection were inconsistent across densities (Fig. 3.2B; interaction term: $F_{2,65}=3.580, p=0.034$ ). I ran pairwise comparisons of the linear selection differential on size between density treatments to identify these differences. I found a significant difference between low and mid densities $\left(\chi^{2}{ }_{1}=6.827\right.$, $p=0.027)$, but no significant difference between high and low $\left(\chi^{2}{ }_{1}=3.324, p=0.137\right)$ or high and mid densities $\left(\chi^{2}{ }_{1}=3.327, p=0.137\right)$. Linear selection was moderate and positive in the low density treatment $\left(S_{T L}=0.456, S E=0.283 ; F_{1,17}=2.583, p=0.126\right)$, weak and negative in the mid density treatment $\left(S_{T L}=-0.201, S E=0.142 ; F_{1,17}=1.200, p\right.$ $=0.176)$, and non-directional in the high density treatment $\left(S_{T L}=0.037, \mathrm{SE}=0.077 ; F_{1,27}\right.$ $=0.235, p=0.632$ ). However, linear selection was not significant in any density treatment, and this is likely a result of the relatively high variability of the selection differentials. I also found no significant non-linear selection on size $\left(C_{T L}=0.0706, \mathrm{SE}=\right.$ $0.0887 ; F_{1,65}=0.634, p=0.429$ ), and this was consistent across densities (interaction term: $\left.F_{2,63}=0.917, p=0.405\right)$. I evaluated a reduced model without the interaction term, and the results of the reduced model were qualitatively similar to those of the full model; there was no significant non-linear selection on size $\left(C_{T L}=0.089, \mathrm{SE}=0.0755\right.$; $\left.F_{1,67}=1.397, p=0.241\right)$. 


\subsection{2 - Selective predation as a function of age, larval growth history, and density}

For larval stage F. lapillum, I sequentially removed non-significant interactions from the linear selection model to determine a reduced model with only one interaction term. I found significant linear selection on larval growth rate (Fig. 3.2C; $\beta_{b}=-0.167, S E=0.070$; $\left.F_{1,129}=5.605, p=0.018\right)$, however, patterns of linear selection on larval growth rate were not consistent across densities (interaction term: $F_{2,129}=13.905, p<0.001$ ). I ran pairwise comparisons of the linear selection gradients between densities, and found significant differences for each comparison (High-Low: $\chi^{2}{ }_{1}=27.679, p<0.001$; High-Mid: $\chi^{2}{ }_{1}=0.179, p=0.020$; Low-Mid: $\left.\chi^{2}{ }_{1}=-0.209, p=0.020\right)$. Linear selection on larval growth rate was strong in the low density treatment $\left(\beta_{b}=-0.662, S E=0.147 ; F_{1,31}=20.365, p<\right.$ $0.001)$, moderate in the mid density treatment $\left(\beta_{b}=-0.417, S E=0.087 ; F_{1,36}=22.988, p\right.$ $<0.001)$, and non-directional in the high density treatment $\left(\beta_{b}=-0.058, S E=0.086 ; F_{1,56}\right.$ $=0.454, p=0.503)$. I found no significant linear selection on larval age $\left(\beta_{P L D}=0.004, S E\right.$ $\left.=0.063 ; F_{1,129}=0.005, p=0.944\right)$, and this pattern was consistent across densities (interaction term: $F_{2,127}=1.797, p=0.170$ ). In the non-linear selection model, no interaction terms were found to be significant, and I evaluated a reduced model with only the main effects. I found no significant non-linear selection on larval growth rate $\left(\nu_{b}=-0.053, S E=0.058 ; F_{1,131}=2.141, p=0.146\right)$ or larval age $\left(\nu_{b}=0.023, S E=0.049\right.$; $\left.F_{1,131}=2.226, p=0.138\right)$.

For juveniles, I sequentially removed non-significant interactions from the linear selection model to determine a reduced model with only one significant interaction term. Linear selection on larval growth rate was negative but weak (Fig. 3.2D; $\beta_{b}=-$ $\left.0.183, \mathrm{SE}=0.090 ; \mathrm{F}_{1,62}=4.240, \mathrm{p}=0.044\right)$, indicating juveniles who grew quickly during the larval stage had slightly reduced fitness. This pattern was consistent across densities (interaction term: $F_{2,60}=1.022, p=0.366$ ). I found no significant linear selection on larval age $\left(\beta_{P L D}=0.045, S E=0.080 ; F_{1,62}=0.323, p=0.572\right)$, and this was also consistent across densities (interaction term: $F_{2,58}=0.282, p=0.755$ ). I found no linear selection on late larval growth $\left(\beta_{L L G}=0.003, S E=0.092 ; F_{1,62}=0.001, p=0.972\right)$; however, patterns of linear selection on late larval growth were not consistent across densities (Fig. 3.3; interaction term: $F_{2,62}=4.776, p=0.012$ ). To identify these differences, I rain pairwise 
comparisons of linear selection between density treatments. Linear selection in the low density treatment was significantly different to that in both the high $\left(\chi^{2}{ }_{1}=8.458, p=\right.$ $0.011)$ and mid $\left(\chi^{2}{ }_{1}=5.935, p=0.030\right)$ density treatments. There was no significant difference in linear selection between mid and high densities $\left(\chi^{2}{ }_{1}=0.050, p=0.823\right)$. While linear selection on late larval growth was strong and positive in the low density treatment $\left(\beta_{L L G}=0.527, S E=0.233 ; F_{1,15}=5.100, p=0.039\right)$, it was non-directional in the $\operatorname{mid}\left(\beta_{P S G}=0.057, S E=0.124 ; F_{1,15}=0.213, p=0.651\right)$ and high $\left(\beta_{P S G}=-0.044, S E=0.055\right.$; $F_{1,24}=0.649, p=0.429$ ) density treatments. 

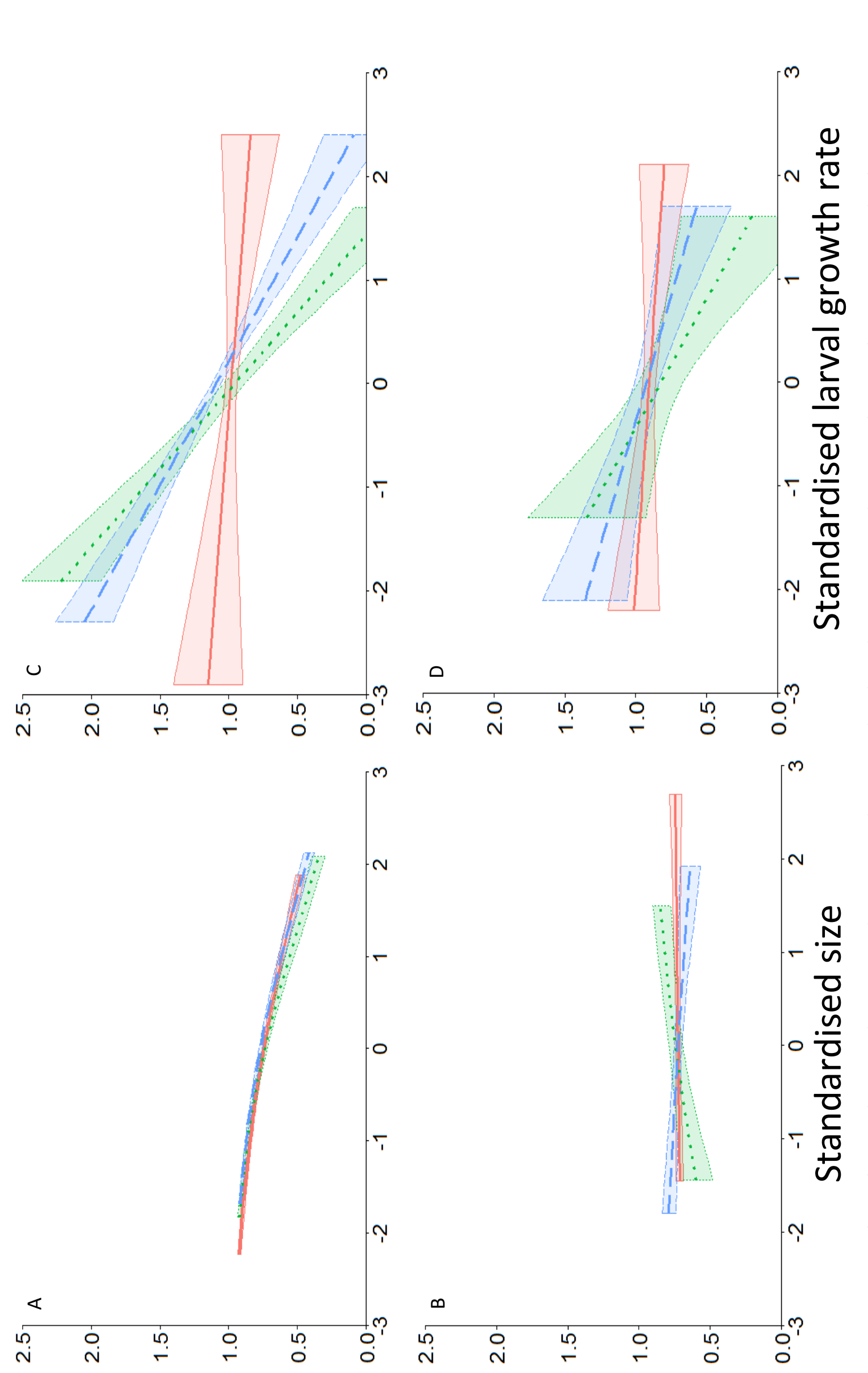

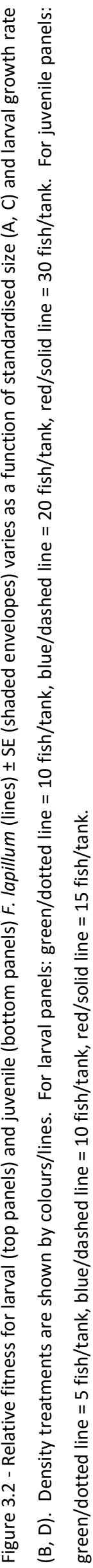

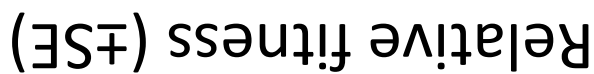




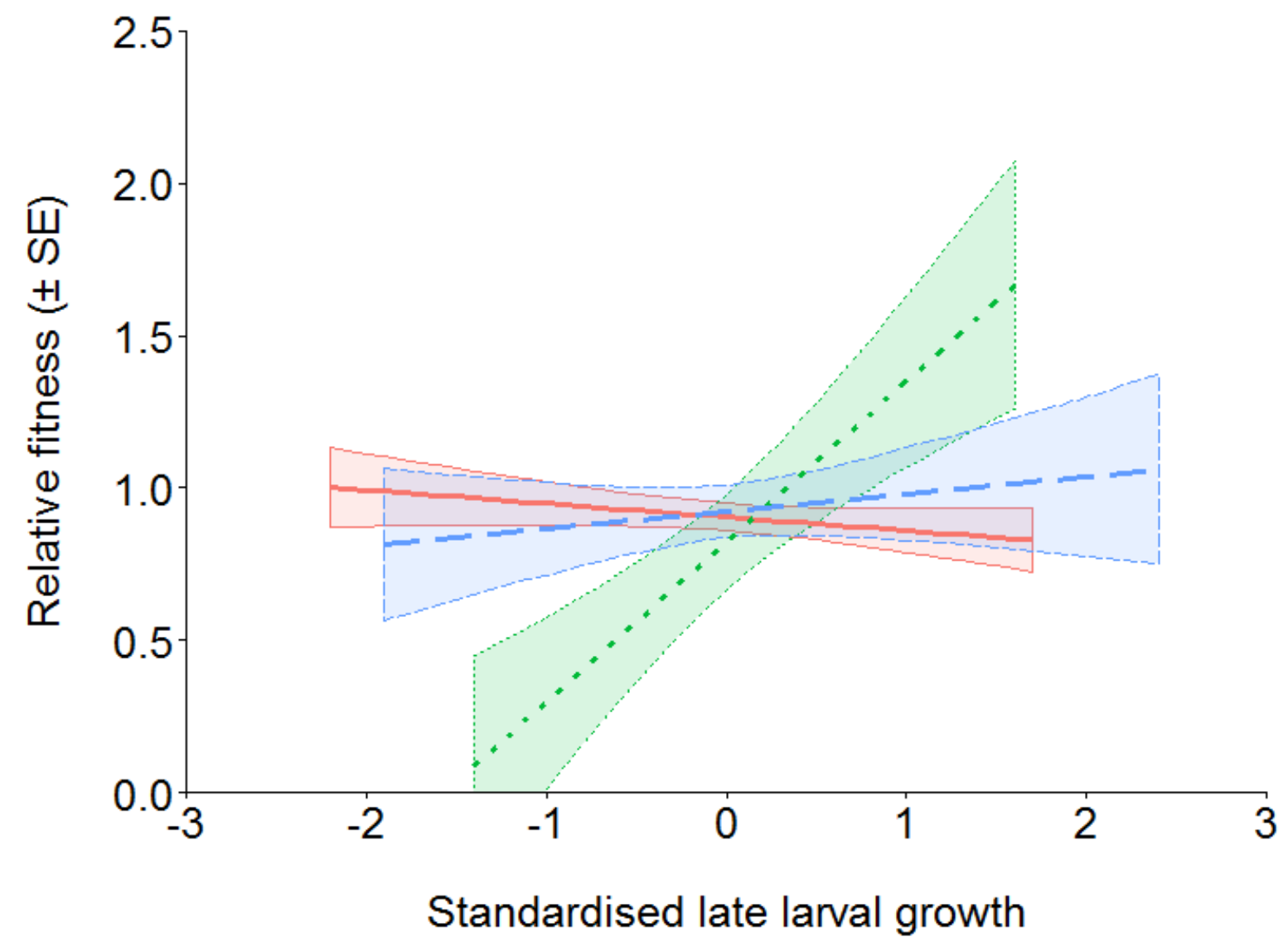

Figure 3.3 - Relative fitness for juvenile F. lapillum (lines) \pm SE (shaded envelopes) varies as a function of standardised late larval growth. Density treatments are shown by colours/lines: green/dotted line $=5$ fish/tank, blue $/$ dashed line $=10$ fish/tank, red/solid line $=15$ fish/tank.

In the non-linear selection model, I found a significant four-way interaction between growth history traits and density, so I evaluated a separate model for each density. All interaction terms and main effects were non-significant $(p>0.050)$, indicating no change in variance or co-variance of traits after adjusting for linear selection.

\section{4 - Discussion}

The main purpose of this chapter was to test both the 'bigger-is-bigger' and 'faster-isbetter' hypotheses using the predator-prey system of $F$. lapillum and $F$. varium. Additionally, I asked whether patterns of selection change with conspecific density, or between ontogenetic stages. 


\subsection{1 - Selective mortality on larval stage $F$. lapillum}

Although linear size-selection was found at all densities for larval stage triplefins, linear growth-selection was only found at low and mid densities. Given that growth rates and size should be correlated, this pattern seems counterintuitive at first - however, it may be that the mechanism of selection changes with density. Prey behaviour has been found to influence predation vulnerability, and it may be that faster growing larvae are more likely to encounter predators, particularly if faster growth is attained through increased foraging and food consumption. Assuming the larger individuals are those that are also foraging in the presence of predators, linear size- and growth-selection at low and mid densities may be driven by larval F. lapillum behaviour. Behaviour may be less influential at high densities; greater prey abundance may simply result in more predator-prey encounters. As such, predators may actively select certain phenotypes over others (e.g., larger larvae regardless of growth history) instead of only consuming prey they encounter (e.g., larger larvae with fast growth). This could result in sizeselection at all densities, while also allowing for changes in growth-selection across densities. This is supported further by the finding of negative non-linear selection (a reduction in the variance of the trait, independent of changes associated with linear selection) occurring on size but not growth rates - as many growth pathways may produce individuals of the same size, variability in growth rates was not changed by predation.

Studies on young fish suggest that larger individuals often experience increased survival (reviewed in Perez and Munch 2010), and support for the 'bigger-is-better' hypothesis is typically found in predator-prey systems where the predator is gape-limited. However, F. varium were capable of consuming the largest larval or juvenile stage $F$. lapillum in my trials, which suggests that gape-limition does not exists in this predatorprey system. This study did not identify the mechanisms of size-selection, but it may be that bigger larvae are simply more conspicuous to predators due to their larger body size. F. varium appear to be visual predators (P Caie, pers. obs.), and they may be actively selecting larger individuals as they are more profitable prey items. Other studies have also found that 'high' condition fish can be selectively preyed upon by predators 
(Hoey and McCormick 2004, Holmes and McCormick 2009). Additionally, larger individuals may be engaging in riskier behaviour that increases exposure to predators, such as elevated foraging rates - if these individuals were foraging instead of using refuge, predators may be more likely to encounter and consume larger larvae. Faster growing larvae also had reduced fitness; assuming faster growth is facilitated by increased foraging, size- and growth-selective mortality may be a result of foraging behaviour (Steele and Forrester 2002, Biro et al. 2003b, c, Biro et al. 2004). Differences in selection intensity across densities have been found elsewhere, with selection strongest at low densities and weakest or non-directional at high densities due to differences in predator foraging patterns (Hansen and Beauchamp 2014) or trait variance (Murphy et al. 2014).

\subsection{2 - Selective mortality on juvenile stage $F$. lapillum}

Juvenile stage $F$. lapillum experienced no size-selective predation. If growth rates influence both the size and behaviour of individuals, a lack of size-selection may indicate a reduction in risky behaviour such as foraging in the presence of a predator. Assuming individuals that were more willing to participate in this risky behaviour have been removed from the population earlier (e.g., in the larval stage), then selection driven by this behaviour will also be removed from later ontogenetic stages (e.g., in the juvenile stage). Alternatively, juveniles may have learnt to avoid or reduce risky behaviour in the presence of a predator. Although F. varium may not be consuming juveniles based on size, size-selection may occur in the field through other selection pressures - a previous study determined that smaller F. lapillum juveniles are more vulnerable to cannibalism by F. lapillum adults (Mensink and Shima 2014). While linear selection on larval growth did occur for juvenile stage F. lapillum, selection against fast larval growth was comparatively weaker in the juvenile stage $\left(\beta_{b} \pm S E=-0.183 \pm 0.080\right)$ than in the larval stage at both low $\left(\beta_{b}=-0.662 \pm 0.147\right)$ and mid $\left(\beta_{b}=-0.417 \pm 0.087\right)$ densities. The opportunity for and potential strength of selection is greatest when variance in relative fitness is high (Brodie et al. 1995); this difference in the strength of selection between ontogenetic stages may occur if variability in relative fitness has already been removed before settlement (i.e., during the larval stage in the field). Unlike larval stage $F$. 
lapillum, juveniles experienced selection against fast larval growth across all densities; this may be because the highest juvenile density $(n=15)$ was comparable to the lowest larval density $(n=10)$ - I may have observed a similar density-dependent pattern in selection if higher juvenile densities were used, but the biological relevance of this question is limited due to the naturally low recruitment rates of juvenile triplefins in the field. Selection on late larval growth was only found in the lowest density treatment, where individuals that had grown quickly immediately before settlement had greater relative fitness. Fast growth in this period may be correlated with higher postsettlement condition (Searcy and Sponaugle 2001, Hamilton 2008, Shima et al. 2015) recruits with this growth history may also be important for population stability and increased adult densities because they tend to have better post-settlement survival (Booth and Hixon 1999, Hamilton et al. 2008, Noonburg et al. 2015). Reef fish with poor condition at and shortly after settlement can be more susceptible to predation (Booth and Hixon 1999, Booth and Beretta 2004); for fish that grew slowly immediately before settlement, there may be pressure to 'catch-up' by increasing foraging rates postsettlement. As for larval fish, greater foraging in the presence of predators may increase vulnerability to predators. Slow growth immediately before settlement may have other physiological costs such as lower swimming speed or slower reaction times, which could increase chances of predation. These 'poor' quality individuals may be the only prey encountered at low densities, but as density (and predator-prey encounters) increases, the cost to relative fitness of this particular phenotype is reduced. No non-linear selection was found on juvenile early life-history traits; although this suggests that there were no changes in the variance or covariance of the traits, it may also reflect the inherently high variability that is associated with smaller sample sizes.

\subsection{3 - Conclusions}

This chapter was an attempt to reproduce pulsed selection pressures on young triplefins, not long-term trends in selection. These results highlight how selection can change with ontogeny, and it would be unsurprising to find further switches in direction or strength of selection as an individual matures. This work found no evidence that larger or faster growing individuals had greater relative fitness, and provides yet another 
example of carry-over effects in marine organisms. It also highlights the need for more frequent sampling throughout ontogenetic shifts for a more complete appreciation of selection directions and strengths, as well as how these may change as a function of density.

Assuming young triplefins experience similar patterns of selective mortality in the field, these findings could explain the presence of apparently low quality individuals (e.g. fish with slow larval growth) in the juvenile stage. When larval density is low, faster growing individuals have reduced fitness, and poor quality larvae have greater survival to the juvenile stage. At greater densities, selective mortality on growth is removed, and high quality individuals are maintained in the cohort. Although low quality fish may survive settlement, longitudinal studies suggest that individuals with this cautious growth pathway experience greater mortality throughout the juvenile period (Shima and Swearer 2010). For the common triplefin, living dangerously in the early life stages may have greater long-term gains. 


\section{Chapter 4 - General conclusions}

\section{1 - Summary of findings}

Both larval and juvenile Forsterygion lapillum show substantial variability in their early life-history traits, which suggests cohorts may be composed of individuals of varying quality and provide an opportunity for selective mortality to occur. Although larvae exhibited temporal variation in early life-history traits, there were no discernible patterns. However, juveniles showed clear seasonal differences in early life-history traits, as well as regional differences for early larval growth and site-specific differences for larval growth rates. These differences in patterns of variability are likely a result in the differences of sampling scales; larval F. lapillum were collected at a much finer scale (i.e., nightly sampling over two weeks from five sites along a $\sim 5 \mathrm{~km}$ stretch of coast) compared to juveniles (i.e., approximately weekly sampling over four months from two different regions - harbour and coastal sites). In addition, juveniles were also larger at hatch and grew more slowly during the larval period compared to larvae, providing circumstantial evidence for selective mortality of faster growing individuals around settlement. While early larval growth was positively correlated with density for sampled larvae, no relationship was found between early life-history traits and recruitment for sampled juveniles. Correlations between larval growth rates and recruitment strength have been found in many other systems (e.g., Bergenius et al. 2002, Wilson and Osenberg 2002, Jenkins and King 2006, Fontes et al. 2010) and may be indicative of favourable growing conditions during the larval stage resulting in lowered mortality. No relationship between early life-history traits and density for juveniles may be a result of spatial or temporal differences in developmental environments (e.g., Meekan and Fortier 1996, Robert et al. 2007, Grorud-Colvert and Sponaugle 2011, Rankin and Sponaugle 2011a); conditions that drive the relationship between early larval growth and density in the year or location that larvae were sampled in may be different to the conditions present in the year or location juveniles were sampled in. Alternatively, if individuals with fast early larval growth are indeed removed around settlement, 
selective mortality may be masking this relationship for juveniles sampled postsettlement.

In my predation trials, I found evidence for both size- and growth-selective mortality, although patterns of selection changed with both density and ontogeny. The largest and fastest growing larvae were selectively consumed by their predator, however the strength of selection weakened as density increased. Juveniles did not experience any size-selection, but were subject to mortality on larval growth traits, suggesting the presence of carry-over effects. As with larvae, juveniles who grew quickly during the larval stage were removed by predators, although the strength of selection was substantially weaker than that experienced by larvae. Selection is strongest when variance in relative fitness is highest, and juveniles used in the predation trials may have already experienced selective mortality on early life-history traits before collection (i.e., as larvae). In contrast to selection on larval growth rate, I found selection for fast late larval growth in juveniles; faster growth during this period of development may be positively correlated with post-settlement fitness. As such, these trials would suggest that the 'best' developmental pathway for the common triplefin is slow growth during the larval stage, followed by a period of fast growth immediately before settlement. However, as mortality of pelagic larvae typically increases with time spent in the plankton (Pepin 1991, Leggett and Deblois 1994, O'Connor et al. 2007, Cowen and Sponaugle 2009), very slow growth (and therefore, longer pelagic larval durations) is likely to come with its own costs. As such, larvae likely experience trade-offs between growing too quickly (e.g., increased predation vulnerability) and too slowly (e.g., increased pelagic mortality rates).

These results suggest that there is an opportunity for selection to occur in the field on early life stages of F. lapillum, with circumstantial evidence for selective mortality against faster larval growth. This preliminary finding is concordant with my predation trials, which provide a potential agent of selection - predation around settlement. Importantly, these predation trials identified shifts in patterns of selection due to ontogeny and density, highlighting the need to consider how the strength and direction 
of selection can be altered by differences in life stages or conspecific density. Changes in selective mortality with density (Brunton and Booth 2003, Holmes and McCormick 2006, Johnson 2008, Samhouri et al. 2009, Fontes et al. 2010, Hansen and Beauchamp 2014, Johnson et al. 2014, Murphy et al. 2014) or through ontogeny (Schluter et al. 1991, Hoekstra et al. 2001, Gagliano et al. 2007, Johnson and Hixon 2010, D'Alessandro et al. 2013, Sun et al. 2015) have been found in other studies, suggesting this may be a common feature of selective mortality in the field.

\section{2 - Future directions}

Chapter 2 made use of two datasets collected in different years and at different locations. Although I was still able to describe variability within the cohorts, a more accurate analysis could be made from frequent longitudinal sampling of multiple cohorts throughout the recruitment season. Spatial and temporal differences could be confirmed by annually sampling at different sites for several years. This would determine how consistent spatial and temporal differences in recruitment and trait variability actually are, and would allow identification of phenotypic shifts through ontogeny.

Within each predation trial, my sample size was small ( $n=5$ to 30 ), but these densities were chosen to represent natural recruitment densities in an attempt to produce ecologically relevant results. My intentions were to run more replicates of each treatment to overcome the small sample size, but I was constrained by the length of the sampling season and the number of larval and juvenile triplefins I was able to collect. Young F. lapillum in the Wellington region are typically only present from late November to early March, and recruitment in this year was substantially lower than previous years. Despite this, I still found significant selection patterns on growth and size - increased replications could have reduced the variability in my results, and improved the strength of my findings.

One considerable limitation to my predation trials is the presence of only a single mechanism of selection, namely predation via F. varium. Forsterygion lapillum are likely 
consumed by a suite of predators in the field, including adult conspecifics. Other selection processes are also likely to exist concurrently, and these may dampen or enhance strength of size- and growth-selective mortality. Other prey in the field may alter selective processes on F. lapillum by reducing rates of predation. My experimental design could not identify the causal mechanism for size- and growth-selective mortality - future studies could determine how prey or predator behaviour influences vulnerability of larger and faster growing fish. For example, behavioural tests of prey may reveal increased foraging and reduced refuge use in the presence of predators, which has been found elsewhere. Alternatively, predators may actively be selecting for the most valuable prey items; identifying prey value, and associated capture and handling costs could determine if $F$. varium conform to optimal foraging theory. 
Appendix

Appendix 1 - Mortality rates for predation trials

\begin{tabular}{|c|c|c|c|c|}
\cline { 2 - 5 } \multicolumn{1}{c|}{} & \multicolumn{2}{c|}{ Larvae } & \multicolumn{2}{c|}{ Juveniles } \\
\hline Density & Block 1 & Block 2 & Block 1 & Block 2 \\
\hline Low (1) & 0.40 & 0.60 & 0.00 & 0.40 \\
Low (2) & 0.50 & 0.30 & 0.80 & 0.20 \\
Mid & 0.20 & 0.40 & 0.30 & 0.30 \\
High & 0.27 & 0.47 & 0.33 & 0.27 \\
\hline
\end{tabular}




\section{Bibliography}

Abrams, P. A., and L. Rowe. 1996. The effects of predation on the age and size of maturity of prey. Evolution 50:1052-1061.

Allen, R. M., and D. J. Marshall. 2014. Egg size effects across multiple life-history stages in the marine annelid Hydroides diramphus. PLoS One 9:e102253.

Almany, G. R. 2004. Differential effects of habitat complexity, predators and competitors on abundance of juvenile and adult coral reef fishes. Oecologia 141:105-113.

Almany, G. R., and M. S. Webster. 2005. The predation gauntlet: Early post-settlement mortality in reef fishes. Coral Reefs 25:19-22.

Anderson, J. T. 1988. A review of size dependent survival during pre-recruit stages of fishes in relation to recruitment. Journal of Northwest Atlantic Fishery Science 8:55-66.

Audzijonyte, A., A. Kuparinen, and E. A. Fulton. 2012. How fast is fisheries-induced evolution? Quantitative analysis of modelling and empirical studies. Evolutionary Applications 5:585595.

Bachiller, E., U. Cotano, L. Ibaibarriaga, M. Santos, and X. Irigoien. 2015. Intraguild predation between small pelagic fish in the Bay of Biscay: Impact on anchovy (Engraulis encrasicolus L.) egg mortality. Marine Biology 162:1351-1369.

Bailey, K. M., and E. D. Houde. 1989. Predation on eggs and larvae of marine fishes and the recruitment problem. Pages 1-83 in J. H. S. Blaxter and A. J. Southward, editors. Advances in Marine Biology. Academic Press.

Bastrikin, D. K., A. Gallego, C. P. Millar, I. G. Priede, and E. G. Jones. 2014. Settlement length and temporal settlement patterns of juvenile cod (Gadus morhea), haddock (Melanogrammus aeglefinus), and whiting (Merlangius merlangus) in a northern North Sea coastal nursery area. International Council for the Exploration of the Sea 71:2101-2113.

Bates, D., M. Maechler, B. Bolker, S. Walker, R. H. B. Christensen, H. Singmann, B. Dai, and G. Grothendieck. 2015. Linear mixed-effects models using 'Eigen' and S4.

Bauer, L. J., and T. J. Miller. 2010. Spatial and interannual variability in winter mortality of the blue crab (Callinectes sapidus) in the Chesapeake Bay. Estuaries and Coasts 33:678-687.

Baumann, H., H.-H. Hinrichsen, C. Möllmann, F. W. Köster, A. M. Malzahn, and A. Temming. 2006. Recruitment variability in Baltic Sea sprat (Sprattus sprattus) is tightly coupled to temperature and transport patterns affecting the larval and early juvenile stages. Canadian Journal of Fisheries and Aquatic Sciences 63:2191-2201.

Beaugrand, G., K. M. Brander, A. Lindley, S. Souissi, and P. C. Reid. 2003. Plankton effect on cod recruitment in the North Sea. Nature 426:661-664. 
Benton, T. G., S. J. Plaistow, and T. N. Coulson. 2006. Complex population dynamics and complex causation: Devils, details and demography. Proceedings of the Royal Society B 273:11731181.

Bergenius, M. A. J., M. G. Meekan, D. R. Robertson, and M. I. McCormick. 2002. Larval growth predicts the recruitment success of a coral reef fish. Oecologia 131:521-525.

Berkeley, S. A., C. Chapman, and S. M. Sogard. 2004. Maternal age as a determinant of larval growth and survival in a marine fish, Sebastes melanops. Ecology 85:1259-1264.

Beukema, J. J., and R. Dekker. 2014. Variability in predator abundance links winter temperatures and bivalve recruitment: Correlative evidence from long-term data in a tidal flat. Marine Ecology Progress Series 513:1-15.

Beukers, J. S., and G. P. Jones. 1998. Habitat complexity modifies the impact of piscivores on a coral reef fish population. Oecologia 114:50-59.

Bijleveld, A. I., S. Twietmeye, J. Piechock, J. A. van Gils, and T. Piersma. 2015. Natural selection by pulsed predation: Survival of the thickest. Ecology 96:1943-1956.

Billerbeck, J. M., T. E. Lankford, and D. O. Conover. 2001. Evolution of intrinsic growth and energy acquisition rates. I. Trade-offs with swimming performance in Menidia menidia. Evolution 55:1863-1872.

Biro, P. A., M. V. Abrahams, J. R. Post, and E. A. Parkinson. 2004. Predators select against high growth rates and risk-taking behaviour in domestic trout populations. Proceedings of the Royal Society B 271:2233-2237.

Biro, P. A., and J. R. Post. 2008. Rapid depletion of genotypes with fast growth and bold personality traits from harvested fish populations. Proceedings of the National Academy of Sciences of the United States of America 105:2919-2922.

Biro, P. A., J. R. Post, and M. V. Abrahams. 2005. Ontogeny of energy allocation reveals selective pressure promoting risk-taking behaviour in young fish cohorts. Proceedings of the Royal Society B 272:1443-1448.

Biro, P. A., J. R. Post, and E. A. Parkinson. 2003a. Density-dependent mortality is mediated by foraging activity for prey fish in whole-lake experiments. Journal of Animal Ecology 72:546555.

Biro, P. A., J. R. Post, and E. A. Parkinson. 2003b. From individuals to populations: Prey fish risktaking mediated mortality in whole-system experiments. Ecology 84:2419-2431.

Biro, P. A., J. R. Post, and E. A. Parkinson. 2003c. Population consequences of a predator-induced habitat shift by trout in whole-lake experiments. Ecology 84:691-700. 
Bjørnstad, O. N., J. M. Fromentin, N. C. Stenseth, and J. Gjosaeter. 1999. Cycles and trends in cod populations. Proceedings of the National Academy of Sciences of the United States of America 96:5066-5071.

Bjørnstad, O. N., and T. F. Hansen. 1994. Individual variation and population dynamics. Oikos 69:167171.

Blanchard, J. L., K. T. Frank, and J. E. Simon. 2003. Effects of condition on fecundity and total egg production of eastern Scotian Shelf haddock (Melanogrammus aeglefinus). Canadian Journal of Fisheries and Aquatic Sciences 60:321-332.

Blaxter, J. H. S., and F. G. T. Holliday. 1963. The behaviour and physiology of herring and other clupeids. Pages 261-394 in F. S. Russell, editor. Advances in Marine Biology. Academic Press.

Block, H. E., and M. A. Steele. 2014. Spatial variation in selective mortality on larval traits in the coral reef fish Chromis viridis. Marine Ecology Progress Series 509:303-308.

Bodin, M., Å. Brännström, and U. Dieckmann. 2012. A systematic overview of harvesting-induced maturation evolution in predator-prey systems with three different life-history tradeoffs. Bulletin of Mathematical Biology 74:2842-2860.

Bonhomme, F., and S. Planes. 2000. Some evolutionary arguments about what maintains the pelagic interval in reef fishes. Environmental Biology of Fishes 59:365-383.

Booth, D. J. 1995. Juvenile groups in a coral-reef damselfish: Density-dependent effects on individual fitness and population demography. Ecology 76:91-106.

Booth, D. J., and G. A. Beretta. 2004. Influence of recruit condition on food competition and predation risk in a coral reef fish. Oecologia 140:289-294.

Booth, D. J., and M. A. Hixon. 1999. Food ration and condition affect early survival of the coral reef damselfish, Stegastes partitus. Oecologia 121:364-368.

Boucher, J. M., C. S. Chen, Y. F. Sun, and R. C. Beardsley. 2013. Effects of interannual environmental variability on the transport-retention dynamics in haddock Melanogrammus aeglefinus larvae on Georges Bank. Marine Ecology Progress Series 487:201-215.

Bowen, W. D., C. E. den Heyer, J. I. McMillan, and S. J. Iverson. 2015. Offspring size at weaning affects survival to recruitment and reproductive performance of primiparous gray seals. Ecology and Evolution 5:1412-1424.

Brodie, E. D., A. Moore, and F. Janzen. 1995. Visualizing and quantifying natural selection. Trends in Ecology and Evolution 10:313-318.

Brunton, B. J., and D. J. Booth. 2003. Density- and size-dependent mortality of a settling coral-reef damselfish (Pomacentrus moluccensis Bleeker). Oecologia 137:377-384. 
Burgess, S. C., and D. J. Marshall. 2011. Are numbers enough? Colonizer phenotype and abundance interact to affect population dynamics. Journal of Animal Ecology 80:681-687.

Burgess, S. C., and D. J. Marshall. 2014. Adaptive parental effects: The importance of estimating environmental predictability and offspring fitness appropriately. Oikos 123:769-776.

Burgess, S. C., E. A. Treml, and D. J. Marshall. 2012. How do dispersal costs and habitat selection influence realized population connectivity? Ecology 93:1378-1387.

Caley, M. J., M. H. Carr, M. A. Hixon, T. P. Hughes, G. P. Jones, and B. A. Menge. 1996. Recruitment and the local dynamics of open marine populations. Annual Review of Ecology and Systematics 27:477-500.

Campana, S. 1996. Year-class strength and growth rate in young Atlantic cod. Marine Ecology Progress Series 135:21-26.

Campana, S. E., and J. D. Neilson. 1985. Microstructure of fish otoliths. Canadian Journal of Fisheries and Aquatic Sciences 42:1014-1032.

Cargnelli, L. M., and M. R. Gross. 1996. The temporal dimension in fish recruitment: Birth date, body size, and size-dependent survival in a sunfish (Bluegill: Lepomis macrochirus). Canadian Journal of Fisheries and Aquatic Sciences 53:360-367.

Carlson, S. M., E. M. Olsen, and L. A. Vøllestad. 2008. Seasonal mortality and the effect of body size: A review and an empirical test using individual data on brown trout. Functional Ecology 22:663-673.

Carr, M. H., T. W. Anderson, and M. A. Hixon. 2002. Biodiversity, population regulation, and the stability of coral-reef fish communities. Proceedings of the National Academy of Sciences 99:11241-11245.

Carroll, J. M., J. P. Marion, and C. M. Finelli. 2015. A field test of the effects of mesopredators and landscape setting on juvenile oyster, Crassostrea virginica, consumption on intertidal reefs. Marine Biology 162:993-1003.

Castonguay, M., S. Plourde, D. Robert, J. A. Runge, and L. Fortier. 2008. Copepod production drives recruitment in a marine fish. Canadian Journal of Fisheries and Aquatic Sciences 65:15281531.

Castorani, M. C. N., and K. A. Hovel. 2015. Invasive prey indirectly increase predation on their native competitors. Ecology 96:1911-1922.

Chaparro, O. R., C. J. Segura, S. J. A. Osores, J. A. Pechenik, L. M. Pardo, and V. M. Cubillos. 2014. Consequences of maternal isolation from salinity stress for brooded embryos and future juveniles in the estuarine direct-developing gastropod Crepipatella dilatata. Marine Biology 161:619-629. 
Conover, D. O., and S. B. Munch. 2002. Sustaining fisheries yields over evolutionary time scales. Science 297:94-96.

Coulson, T., T. G. Benton, P. Lundberg, S. R. X. Dall, B. E. Kendall, and J. M. Gaillard. 2006. Estimating individual contributions to population growth: Evolutionary fitness in ecological time. Proceedings of the Royal Society B-Biological Sciences 273:547-555.

Cowen, R. K., and S. Sponaugle. 2009. Larval dispersal and marine population connectivity. Annual Review of Marine Science 1:443-466.

Crean, A. J., K. Monro, and D. J. Marshall. 2011. Fitness consequences of larval traits persist across the metamorphic boundary. Evolution 65:3079-3089.

Cushing, D. H. 1975. Marine ecology and fisheries. Cambridge University Press, Cambridge.

D'Alessandro, E. K., S. Sponaugle, and R. K. Cowen. 2013. Selective mortality during the larval and juvenile stages of snappers (Lutjanidae and Great Barracuda Sphyraena barracuda. Marine Ecology Progress Series 474:227-242.

Dahlgren, C. P., and D. B. Eggleston. 2000. Ecological processes underlying ontogenetic habitat shifts in a coral reef fish. Ecology 81:2227-2240.

Davenport, J. M., B. R. Hossack, and W. H. Lowe. 2014. Partitioning the non-consumptive effects of predators on prey with complex life histories. Oecologia 176:149-155.

Day, T., P. A. Abrams, and J. M. Chase. 2002. The role of size-specific predation in the evolution and diversification of prey life histories. Evolution 56:877-887.

Delorme, N. J., and M. A. Sewell. 2014. Temperature and salinity: Two climate change stressors affecting early development of the New Zealand sea urchin Evechinus chloroticus. Marine Biology 161:1999-2009.

Dibattista, J. D., K. A. Feldheim, S. H. Gruber, and A. P. Hendry. 2007. When bigger is not better: Selection against large size, high condition and fast growth in juvenile lemon sharks. Journal of Evolutionary Biology 20:201-212.

Dmitriew, C. M. 2011. The evolution of growth trajectories: What limits growth rate? Biological Reviews 86:97-116.

Doherty, P. J., V. Dufour, R. Galzin, M. A. Hixon, M. G. Meekan, and S. Planes. 2004. High mortality during settlement is a population bottleneck for a tropical surgeonfish. Ecology 85:24222428.

Doherty, P. J., and P. F. Sale. 1985. Predation on juvenile coral reef fishes: An exclusion experiment. Coral Reefs 4:225-234.

Donelan, S. C., and G. C. Trussell. 2015. Parental effects enhance risk tolerance and performance in offspring. Ecology 96:2049-2055. 
Donelson, J. M., M. I. McCormick, and P. L. Munday. 2008. Parental condition affects early lifehistory of a coral reef fish. Journal of Experimental Marine Biology and Ecology 360:109-116.

Durant, J. M., D. O. Hjermann, G. Ottersen, and N. C. Stenseth. 2007. Climate and the match or mismatch between predator requirements and resource availability. Climate Research 33:271-283.

Elzhov, T. V., K. M. Mullen, A.-N. Spiess, and B. M. Bolker. 2013. R interface to the LevenbergMarquardt nonlinear leas-squares algorithm found in MINPACK, plus support for bounds.

Feary, D. A., and K. D. Clements. 2006. Habitat use by triplefin species (Tripterygiidae) on rocky reefs in New Zealand. Journal of Fish Biology 69:1031-1046.

Felix-Hackradt, F. C., C. W. Hackradt, J. Trevino-Oton, A. Perez-Ruzafa, and J. A. Garcia-Charton. 2013. Temporal patterns of settlement, recruitment and post-settlement losses in a rocky reef fish assemblage in the south-western Mediterranean Sea. Marine Biology 160:23372352.

Ferguson, G. W., and S. F. Fox. 1984. Annual variation of survival advantage of large juvenile sideblotched lizards, Uta stansburiana: Its causes and evolutionary significance. Evolution 38:342-349.

Fisher, J. P., and W. G. Pearcy. 1988. Growth of juvenile Coho salmon (Oncorhynchus kisutch) off Oregon and Washington, USA, in years of differing coastal upwelling. Canadian Journal of Fisheries and Aquatic Sciences 45:1036-1044.

Fogarty, M. J., M. P. Sissenwine, and E. B. Cohen. 1991. Recruitment variability and the dynamics of exploited marine populations. Trends in Ecology and Evolution 6:241-246.

Fontes, J., P. Afonso, R. S. Santos, and J. E. Caselle. 2010. Temporal variability of larval growth, size, stage duration and recruitment of a wrasse, Coris julis (Pisces: Labridae), from the Azores. Scientia Marina 74:721-729.

Forrester, G. E. 1990. Factors influencing the juvenile demography of a coral reef fish. Ecology 71:1666-1681.

Forrester, G. E. 1995. Strong density-dependent survival and recruitment regulate the abundance of a coral reef fish. Oecologia 103:275-282.

Forrester, G. E., and M. A. Steele. 2004. Predators, prey refuges, and the spatial scaling of densitydependent prey mortality. Ecology 85:1332-1342.

Fouzai, N., A. F. Opdal, C. Jørgensen, and $\varnothing$. Fiksen. 2015. Effects of temperature and food availability on larval cod survival: A model for behaviour in vertical gradients. Marine Ecology Progress Series 529:199-212. 
Francis, M. 2001. Coastal fishes of New Zealand: An identification guide. 3rd edition. Reed Books, Auckland.

Gagliano, M., M. I. McCormick, and M. G. Meekan. 2007. Survival against the odds: Ontogenetic changes in selective pressure mediate growth-mortality trade-offs in a marine fish. Proceedings of the Royal Society B 274:1575-1582.

Gårdmark, A., U. Dieckmann, and P. Lundberg. 2003. Life-history evolution in harvested populations: The role of natural predation. Evolutionary Ecology Research 5:239-257.

Gårdmark, A., N. Jonzén, and M. Mangel. 2006. Density-dependent body growth reduces the potential of marine reserves to enhance yields. Journal of Applied Ecology 43:61-69.

Gardner, J. P. A. 2000. Where are the mussels on Cook Strait (New Zealand) shores? Low seston quality as a possible factor limiting multi-species distributions. Marine Ecology Progress Series 194:123-132.

Giacomini, H. C., D. L. DeAngelis, J. C. Trexler, and M. J. Petrere. 2013. Trait contributions to fish community assembly emerge from trophic interactions in an individual-based model. Ecological Modelling 251:32-43.

Gilliam, J. F., and D. F. Fraser. 1987. Habitat selection under predation hazard: Test of a model with foraging minnows. Ecology 68:1856-1862.

Good, S. P., J. J. Dodson, M. G. Meekan, and D. A. J. Ryan. 2001. Annual variation in size-selective mortality of Atlantic salmon (Salmo salar) fry. Canadian Journal of Fisheries and Aquatic Sciences 58:1187-1195.

Gosselin, L. A., and P.-Y. Qian. 1997. Juvenile mortality in benthic marine invertebrates. Marine Ecology Progress Series 146:265-282.

Green, B. S. 2008. Maternal effects in fish populations. Pages 1-105 in D. W. Sims, editor. Advances in Marine Biology, Vol 54. Elsevier Academic Press Inc, San Diego.

Green, B. S., and M. I. McCormick. 2005. Maternal and paternal effects determine size, growth and performance in larvae of a tropical reef fish. Marine Ecology Progress Series 289:263-272.

Grorud-Colvert, K., and S. Sponaugle. 2006. Influence of condition on behaviour and survival potential of a newly settled coral reef fish, the bluehead wrasse, Thalassoma bifasciatum. Marine Ecology Progress Series 327:279-288.

Grorud-Colvert, K., and S. Sponaugle. 2011. Variability in water temperature affects trait-mediated survival of a newly settled coral reef fish. Oecologia 165:675-686.

Grosberg, R. K., and D. R. Levitan. 1992. For adults only? Supply-side ecology and the history of larval biology. Trends in Ecology \& Evolution 7:130-133. 
Günther, C. C., J.-P. Herrmann, and A. Temming. 2015. Laboratory calibration of optimal growth to deduce in situ feeding conditions of early juvenile sprat Sprattus sprattus from otoliths. Marine Ecology Progress Series 525:199-215.

Hadfield, M. G., and M. F. Strathmann. 1996. Variability, flexibility and plasticity in life histories of marine invertebrates. Oceanologica Acta 19:323-334.

Hamer, P. A., and G. P. Jenkins. 2004. High levels of spatial and temporal recruitment variability in the temperate sparid Pagrus auratus. Marine and Freshwater Research 55:663-673.

Hamilton, S. L. 2008. Larval history influences post-metamorphic condition in a coral-reef fish. Oecologia 158:449-461.

Hamilton, S. L., J. Regetz, and R. R. Warner. 2008. Postsettlement survival linked to larval life in a marine fish. Proceedings of the National Academy of Sciences 105:1561-1566.

Hammerschlag, N., A. C. Broderick, J. W. Coker, M. S. Coyne, M. Dodd, M. G. Frick, M. H. Godfrey, B. J. Godley, D. B. Griffin, K. Hartog, S. R. Murphy, T. M. Murphy, E. R. Nelson, K. L. Williams, M. J. Witt, and L. A. Hawke. 2015. Evaluating the landscape of fear between apex predatory sharks and mobile sea turtles across a large dynamic seascape. Ecology 96:2117-2126.

Hansen, A. G., and D. A. Beauchamp. 2014. Effects of prey abundance, distribution, visual contrast and morphology on selection by a pelagic piscivore. Freshwater Biology 59:2328-2341.

Hare, J. A. 2014. The future of fisheries oceanography lies in the pursuit of multiple hypotheses. ICES Journal of Marine Science 71:2343-2356.

Hare, J. A., and R. K. Cowen. 1997. Size, growth, development, and survival of the planktonic larvae of Pomatomus saltatrix (Pisces: Pomatomidae). Ecology 78:2415-2431.

Hauser, L., and G. R. Carvalho. 2008. Paradigm shifts in marine fisheries genetics: Ugly hypotheses slain by beautiful facts. Fish and Fisheries 9:333-362.

Heinlein, J. M., A. C. Stier, and M. A. Steele. 2010. Predators reduce abundance and species richness of coral reef fish recruits via non-selective predation. Coral Reefs 29:527-532.

Hendry, A. P., B. H. Letcher, and G. Gries. 2003. Estimating natural selection acting on streamdwelling Atlantic salmon: Implications for the restoration of extirpated populations. Conservation Biology 17:795-805.

Hereford, J., T. F. Hansen, and D. Houle. 2004. Comparing strengths of directional selection: How strong is strong? Evolution 58:2133-2143.

Hixon, M. A. 1998. Population dynamics of coral-reef fishes: Controversial concepts and hypotheses. Australian Journal of Ecology 23:192-201. 
Hixon, M. A., T. W. Anderson, K. L. Buch, D. W. Johnson, J. B. McLeod, and C. D. Stallings. 2012. Density dependence and population regulation in marine fish: A large-scale, long-term field manipulation. Ecological Monographs 82:467-489.

Hixon, M. A., and J. P. Beets. 1993. Predation, prey refuges, and the structure of coral-reef fish assemblages. Ecological Monographs 63:77-101.

Hixon, M. A., D. W. Johnson, and S. M. Sogard. 2014. BOFFFFs: On the importance of conserving oldgrowth age structure in fishery populations. ICES Journal of Marine Science: Journal du Conseil 71:2171-2185.

Hixon, M. A., and G. P. Jones. 2005. Competition, predation, and density-dependent mortality in demersal marine fishes. Ecology 86:2847-2859.

Hjort, J. 1914. Fluctuations in the great fisheries of Northern Europe viewed in the light of biological research. Rapports et Procès-Verbaux des Réunions Conseil Permanent International pour l'Exploration de la Mer 20:1-228.

Hoekstra, H. E., J. M. Hoekstra, D. Berrigan, S. N. Vignieri, A. Hoang, C. E. Hill, P. Beerli, and J. G. Kingsolver. 2001. Strength and tempo of directional selection in the wild. Proceedings of the National Academy of Sciences 98:9157-9160.

Hoey, A. S., and M. I. McCormick. 2004. Selective predation for low body condition at the larvaljuvenile transition of a coral reef fish. Oecologia 139:23-29.

Holbrook, S. J., A. J. Brooks, and R. J. Schmitt. 2002a. Predictability of fish assemblages on coral patch reefs. Marine and Freshwater Research 53:181-188.

Holbrook, S. J., A. J. Brooks, and R. J. Schmitt. 2002b. Variation in structural attributes of patchforming corals and in patterns of abundance of associated fishes. Marine and Freshwater Research 53:1045-1053.

Holbrook, S. J., and R. J. Schmitt. 2002. Competition for shelter space causes density-dependent predation mortality in damselfishes. Ecology 83:2855-2868.

Holbrook, S. J., and R. J. Schmitt. 2003. Spatial and temporal variation in mortality of newly settled damselfish: Patterns, causes and co-variation with settlement. Oecologia 135:532-541.

Holmes, T. H., and M. I. McCormick. 2006. Location influences size-selective predation on newly settled reef fish. Marine Ecology Progress Series 317:203-209.

Holmes, T. H., and M. I. McCormick. 2009. Influence of prey body characteristics and performance on predator selection. Oecologia 159:401-413.

Houde, E. D. 1989. Comparative growth, mortality, and energetics of marine fish larvae: Temperature and implied latitudinal effects. Fisheries Bulletins 87:471-495. 
Houde, E. D. 2008. Emerging from Hjort's shadow. Journal of Northwest Atlantic Fishery Science 41:53-70.

Houde, E. D., and C. E. Zastrow. 1993. Ecosystem-specific and taxon-specific dynamic and energetics properties of larval fish assemblages. Bulletin of Marine Science 53:290-335.

Hovenkamp, F. 1990. Growth differences in larval plaice Pleuronectes platessa in the Southern Bight of the North Sea as indicated by otolith increments and RNA/DNA ratios. Marine Ecology Progress Series 58:205-215.

Hunt, H. L., and R. E. Scheibling. 1997. Role of early post-settlement mortality in recruitment of benthic marine invertebrates. Marine Ecology Progress Series 155:69-301.

Huss, M., L. Persson, and P. Byström. 2007. The origin and development of individual size variation in early pelagic stages of fish. Oecologia 153:57-67.

Jenkins, G. P., and D. King. 2006. Variation in larval growth can predict the recruitment of a temperate, seagrass-associated fish. Oecologia 147:641-649.

Johnson, D. W. 2006. Predation, habitat complexity, and variation in density-dependent mortality of temperate reef fishes. Ecology 87:1179-1188.

Johnson, D. W. 2007. Habitat complexity modifies post-settlement mortality and recruitment dynamics of a marine fish. Ecology 88:1716-1725.

Johnson, D. W. 2008. Combined effects of condition and density on post-settlement survival and growth of a marine fish. Oecologia 155:43-52.

Johnson, D. W., M. R. Christie, C. D. Stallings, T. J. Pusack, and M. A. Hixon. 2015. Using postsettlement demography to estimate larval survivorship: A coral reef fish example. Oecologia 179:729-739.

Johnson, D. W., K. Grorud-Colvert, T. L. Rankin, and S. Sponaugle. 2012. Measuring selective mortality from otoliths and similar structures: A practical guide for describing multivariate selection from cross-sectional data. Marine Ecology Progress Series 471:151-163.

Johnson, D. W., K. Grorud-Colvert, S. Sponaugle, and B. X. Semmens. 2014. Phenotypic variation and selective mortality as major drivers of recruitment variability in fishes. Ecology Letters 17:743-755.

Johnson, D. W., and M. A. Hixon. 2010. Ontogenetic and spatial variation in size-selective mortality of a marine fish. Journal of Evolutionary Biology 23:724-737.

Jones, G. P. 1990. The importance of recruitment to the dynamics of a coral reef fish population. Ecology 71:1691-1698.

Kaufman, L., J. Ebersole, J. Beets, and C. C. McIVor. 1992. A key phase in the recruitment dynamics of coral reef fishes: Post-settlement transition. Environmental Biology of Fishes 34:109-118. 
Kerrigan, B. A. 1997. Variability in larval development of the tropical reef fish Pomacentrus amboinensis (Pomacentridae): The parental legacy. Marine Biology 127:395-402.

Kimirei, I. A., I. Nagelkerken, M. Trommelen, P. Blankers, N. van Hoytema, D. Hoeijmakers, C. M. Huijbers, Y. D. Mgaya, and A. L. Rypel. 2013. What drives ontogenetic niche shifts of fishes in coral reef ecosystems? Ecosystems 16:783-796.

Kingsolver, J. G., H. E. Hoekstra, J. M. Hoekstra, D. Berrigan, S. N. Vignieri, C. E. Hill, A. Hoang, P. Gibert, and P. Beerli. 2001. The strength of phenotypic selection in natural populations. The American Naturalist 157:245-261.

Kingsolver, J. G., and D. W. Pfennig. 2007. Patterns and power of phenotypic selection in nature. BioScience 57:561-572.

Kritzer, J. P., and P. F. Sale. 2004. Metapopulation ecology in the sea: From Levins' model to marine ecology and fisheries science. Fish and Fisheries 5:131-140.

Lande, R., and S. J. Arnold. 1983. The measurement of selection on correlated characters. Evolution 37:1210-1226.

Lankford, T. E., Jr., J. M. Billerbeck, and D. O. Conover. 2001. Evolution of intrinsic growth and energy acquisition rates. II. Trade-offs with vulnerability to predation in Menidia menidia. Evolution 55:1873-1881.

Law, R. 2000. Fishing, selection, and phenotypic evolution. ICES Journal of Marine Science 57:659668.

Le Corre, N., L. E. Johnson, G. K. Smith, and F. Guichard. 2015. Patterns and scales of connectivity: Temporal stability and variation within a marine metapopulation. Ecology 96:2245-2256.

Le Galliard, J.-F., J. Clobert, and R. Ferriere. 2004. Physical performance and darwinian fitness in lizards. Nature 432:502-505.

Leak, J. C., and E. D. Houde. 1987. Cohort growth and survival of bay anchovy Anchoa mitchilli larvae in Biscayne Bay, Florida. Marine Ecology Progress Series 37:109-122.

Lecchini, D. 2003. Influence of pelagic and benthic, biotic and abiotic, stochastic and deterministic processes on the dynamics of auto-recruitment of coral reef fish: A review. Cybium 27:167184.

Lecchini, D., C. W. Osenberg, J. S. Shima, C. M. St Mary, and R. Galzin. 2007. Ontogenetic changes in habitat selection during settlement in a coral reef fish: Ecological determinates and sensory mechanisms. Coral Reefs 26:423-432.

Leggett, W. C., and E. Deblois. 1994. Recruitment in marine fishes: Is it regulated by starvation and predation in the egg and larval stages? Netherlands Journal of Sea Research 32:119-134. 
Lonnstedt, O. M., and M. I. McCormick. 2011. Growth history and intrinsic factors influence risk assessment at a critical life transition for a fish. Coral Reefs 30:805-812.

Lonnstedt, O. M., M. I. McCormick, M. G. Meekan, M. C. Ferrari, and D. P. Chivers. 2012. Learn and live: predator experience and feeding history determines prey behaviour and survival. Proceedings of the Royal Society B 279:2091-2098.

Lorenzen, K., and K. Enberg. 2002. Density-dependent growth as a key mechanism in the regulation of fish populations: Evidence from among-population comparisons. Proceedings of the Royal Society of London B: Biological Sciences 269:49-54.

Losos, J. B., T. W. Schoener, and D. A. Spiller. 2004. Predator-induced behaviour shifts and natural selection in field experimental lizard populations. Nature 432:505-508.

Lough, R. G., L. J. Buckley, F. E. Werner, J. A. Quinlan, and K. P. Edwards. 2005. A general biophysical model of larval cod (Gadus morhua) growth applied to populations on Georges Bank. Fisheries Oceanography 14:241-262.

Lundvall, D., R. Svanbäck, L. Persson, and P. Byström. 1999. Size-dependent predation in piscivores: Interactions between predator foraging and prey avoidance abilities. Canadian Journal of Fisheries and Aquatic Sciences 56:1285-1292.

Macpherson, E., and N. Raventos. 2005. Settlement patterns and post-settlement survival in two mediterranean littoral fishes: Influences of early-life traits and environmental variables. Marine Biology 148:167-177.

Maddams, J. C., and M. I. McCormick. 2012. Not all offspring are created equal: Variation in larval characteristics in a serially spawning damselfish. PLoS One 7:10.

Marshall, D. J., T. F. Bolton, and M. J. Keough. 2003a. Offspring size affects the post-metamorphic performance of a colonial marine invertebrate. Ecology 84:3131-3137.

Marshall, D. J., P. J. Krug, E. K. Kupriyanova, M. Byrne, and R. B. Emlet. 2012. The biogeography of marine invertebrate life histories. Annual Review of Ecology, Evolution, and Systematics 43:97-114.

Marshall, D. J., J. A. Pechenik, and M. J. Keough. 2003b. Larval activity levels and delayed metamorphosis affect post-larval performance in the colonial ascidian Diplosoma listerianum. Marine Ecology Progress Series 246:153-162.

Mattingly, H. T., and M. J. Butler. 1994. Laboratory predation on the Trinidadian guppy: Implications for the size-selective predation hypothesis and guppy life history evolution. Oikos 69:54-64.

McCormick, M. I. 2006. Mothers matter: Crowding leads to stressed mothers and smaller offspring in marine fish. Ecology 87:1104-1109. 
McCormick, M. I., and A. S. Hoey. 2004. Larval growth history determines juvenile growth and survival in a tropical marine fish. Oikos 106:225-242.

McCormick, M. I., and B. W. Moloney. 1995. Influence of water temperature during the larval stage on size, age and body condition of a tropical reef fish at settlement. Marine Ecology Progress Series 118:59-68.

McDermott, C. J., and J. S. Shima. 2006. Ontogenetic shifts in microhabitat preference of the temperate reef fish Forsterygion lapillum - Implications for population limitation. Marine Ecology Progress Series 320:259-266.

Meekan, M. G., J. H. Carleton, A. D. McKinnon, K. Flynn, and M. Furnas. 2003. What determines the growth of tropical reef fish larvae in the plankton: Food or temperature? Marine Ecology Progress Series 256:193-204.

Meekan, M. G., and L. Fortier. 1996. Selection for fast growth during the larval life of Atlantic Cod Gadus morhua on the Scotia Shelf. Marine Ecology Progress Series 137:25-37.

Mensink, P. J., and J. S. Shima. 2014. Patterns of co-occurance and interactions between age classes of the common triplefin, Fostergyion lapillum. Marine Biology 161:1285-1298.

Miller, J. M., J. S. Burke, and G. R. Fitzhugh. 1991. Early life history patterns of Atlantic North American flatfish: Likely (and unlikely) factors controlling recruitment. Netherlands Journal of Sea Research 27:261-275.

Miller, T. J., L. B. Crowder, J. A. Rice, and E. A. Marschall. 1988. Larval size and recruitment mechanisms in fishes: Toward a conceptual framework. Canadian Journal of Fisheries and Aquatic Sciences 45:1657-1651 1670.

Moore, M. P., T. Landberg, and H. H. Whiteman. 2015. Maternal investment mediates offspring life history variation with context-dependent fitness consequences. Ecology 96:2499-2509.

Munch, S. B., and D. O. Conover. 2003. Rapid growth results in increased susceptibility to predation in Menidia menidia. Evolution 57:2119-2127.

Murphy, H. M., F. W. Warren-Myers, G. P. Jenkins, P. A. Hamer, and S. E. Swearer. 2014. Variability in size-selective mortality obscures the importance of larval traits to recruitment success in a temperate marine fish. Oecologia 175:1201-1210.

Nemeth, R. S. 1998. The effect of natural variation in substrate architecture on the survival of juvenile bicolor damselfish. Environmental Biology of Fishes 53:129-141.

Neumann, V., F. W. Koster, M. Schaber, and M. Eero. 2014. Recovery in eastern Baltic cod: Is increased recruitment caused by decreased predation on early life stages? ICES Journal of Marine Science. 
Nicieza, A. G., and N. B. Metcalfe. 1999. Costs of rapid growth: The risk of aggression is higher for fast-growing salmon. Functional Ecology 13:793-800.

Nilsson, P. A., and C. Bronmark. 2000. Prey vulnerability to a gape-size limited predator: behavioural and morphological impacts on northern pike piscivory. Oikos 88:539-546.

Noonburg, E. G., A. Chen, J. S. Shima, and S. E. Swearer. 2015. Demographic heterogeneity and the dynamics of open populations. Ecology 96:1159-1165.

O'Connor, M. I., J. F. Bruno, S. D. Gaines, B. S. Halpern, S. E. Lester, B. P. Kinlan, and J. M. Weiss. 2007. Temperature control of larval dispersal and the implications for marine ecology, evolution, and conservation. Proc Natl Acad Sci U S A 104:1266-1271.

Olsen, E. M., S. M. Carlson, J. Gjøsæter, and N. C. Stenseth. 2009. Nine decades of decreasing phenotypic variability in Atlantic cod. Ecology Letters 12:622-631.

Paine, R. T. 1974. Intertidal community structure: Experimental studies on the relationship between a dominant competitor and Its principle predator. Oecologia 15:93-120.

Paine, R. T. 1976. Size-limited predation: An observational and experimental approach with the Mytilus-Pisaster interaction. Ecology 57:858-873.

Pechenik, J. A. 2006. Larval experience and latent effects - Metamorphosis is not a new beginning. Integrative and Comparative Biology 46:323-333.

Pechenik, J. A., D. E. Wendt, and J. N. Jarrett. 1998. Metamorphosis is not a new beginning. BioScience 48:901-910.

Pepin, P. 1991. Effect of temperature and size on development, mortality, and survival rates of the pelagic early life history stages of marine fish. Canadian Journal of Fisheries and Aquatic Sciences 48:503-518.

Pepin, P., T. H. Shears, and Y. de Lafontaine. 1992. Significance of body size to the interaction between a larval fish (Mallotus villosus) and a vertebrate predator (Gasterosteus aculea). Marine Ecology Progress Series 81:1-12.

Perez, K. O., and S. B. Munch. 2010. Extreme selection on size in the early lives of fish. Evolution 64:2450-2457.

Persson, L., J. Andersson, E. Wahlström, and P. Eklöv. 1996. Size-specific interactions in lake systems: Predator gape limitation and prey growth rate and mortality. Ecology 77:900-911.

Petrik, C. M., R. Ji, and C. S. Davis. 2014. Interannual differences in larval haddock survival: Hypothesis testing with a 3D biophysical model of Georges Bank. Fisheries Oceanography 23:521-553. 
Pfaff, M. C., G. M. Branch, J. L. Fisher, V. Hoffmann, A. G. Ellis, and J. L. Largier. 2015. Delivery of marine larvae to shore requires multiple sequential transport mechanisms. Ecology 96:1399-1410.

Phillips, N. E. 2002. Effects of nutrition-mediated larval condition on juvenile performance in a marine mussel. Ecology 83:2562-2574.

Planes, S., and G. Lecaillon. 2001. Caging experiment to examine mortality rates during metamorphosis of coral reef fish larvae. Coral Reefs 20:211-218.

Plard, F., J.-M. Gaillard, T. N. Coulson, A. J. M. Hewison, M. Douhard, F. Klein, D. Delorme, C. Warnant, and C. Bonenfant. 2015. The influence of birth date via body mass on individual fitness in a long-lived mammal. Ecology 96:1516-1528.

Platt, T., C. Fuentes-Yaco, and K. T. Frank. 2003. Spring algal bloom and larval fish survival. Nature 423:398-399.

Post, J. R., and A. B. Prankevicius. 1987. Size-selective mortality in young-of-the-year yellow perch (Perca flavescens): Evidence from otolith microstructure. Canadian Journal of Fisheries and Aquatic Sciences 44:1840-1847.

R Core Team. 2015. R: A language and environment for statistical computing. Vienna, Austria.

Rankin, T. L., and S. Sponaugle. 2011a. Temperature influences selective mortality during the early life stages of a coral reef fish. PLoS One 6:e16814.

Rankin, T. L., and S. Sponaugle. 2011b. Temperature influences selective mortality during the early life stages of a coral reef fish. PLoS One 6:9.

Rankin, T. L., and S. Sponaugle. 2014. Characteristics of settling coral reef fish are related to recruitment timing and success. PLoS One 9:13.

Raventos, N., and E. Macpherson. 2005. Effect of pelagic larval growth and size-at-hatching on postsettlement survivorship in two temperate labrid fish of the genus Symphodus. Marine Ecology Progress Series 285:205-211.

Reznick, D. 1982. The impact of predation on life history evolution in Trinidadian guppies: Genetic basis of observed life history patterns. Evolution 36:1236-1250.

Reznick, D. 1989. Life-history evolution in guppies: 2. Repeatability of field observations and the effects of season on life histories. Evolution 43:1285-1297.

Reznick, D., H. Bryga, and J. A. Endler. 1990. Experimentally induced life-history evolution in a natural population. Nature 346:357-359.

Reznick, D., and J. A. Endler. 1982. The impact of predation on life history evolution in Trinidadian guppies (Poecilia reticulata). Evolution 36:160-177. 
Rice, J. A., T. J. Miller, K. A. Rose, L. B. Crowder, E. A. Marschall, A. S. Trebitz, and D. L. DeAngelis. 1993. Growth rate variation and larval survival: Inferences from an individal-based sizedependent predation model. Canadian Journal of Fisheries and Aquatic Sciences 50:133-142.

Robert, D., M. Castonguay, and L. Fortier. 2007. Early growth and recruitment in Atlantic mackerel Scomber scombrus: Discriminating the effects of fast growth and selection for fast growth. Marine Ecology Progress Series 337:209-219.

Roughgarden, J., S. D. Gaines, and H. P. Possingham. 1988. Recruitment dynamics in complex life cycles. Science 241:1460-1466.

RStudio Team. 2015. RStudio: Integrated Development Environment for R. RStudio, Inc., Boston, MA

Saenz-Agudelo, P., G. P. Jones, S. R. Thorrold, and S. Planes. 2015. Mothers matter: Contribution to local replenishment is linked to female size, mate replacement and fecundity in a fish metapopulation. Marine Biology 162:3-14.

Samhouri, J. F., M. A. Steele, and G. E. Forrester. 2009. Inter-cohort competition drives density dependence and selective mortality in a marine fish. Ecology 90:1009-1020.

Scharf, F. S., F. Juanes, and R. A. Rountree. 2000. Predator size - prey size relationships of marine fish predators: Interspecific variation and effects of ontogeny and body size on trophic-niche breadth. Marine Ecology Progress Series 208:229-248.

Schluter, D., T. D. Price, and L. Rowe. 1991. Conflicting selection pressures and life history trade-offs. Proceedings of the Royal Society of London B: Biological Sciences 246:11-17.

Searcy, S. P., and S. Sponaugle. 2000. Variable larval growth in a coral reef fish. Marine Ecology Progress Series 206:213-226.

Searcy, S. P., and S. Sponaugle. 2001. Selective mortality during the larval-juvenile transition in two coral reef fishes. Ecology 82:2452-2470.

Shima, J. S. 2001a. Recruitment of a coral reef fish: Roles of settlement, habitat, and postsettlement losses. Ecology 82:2190-2199.

Shima, J. S. 2001b. Regulation of local populations of a coral reef fish via joint effects of density- and number-dependent mortality. Oecologia 126:58-65.

Shima, J. S. 2002. Mechanisms of density- and number-dependent population regulation of a coralreef fish. Marine and Freshwater Research 53:175-179.

Shima, J. S., and A. M. Findlay. 2002. Pelagic larval growth rate impacts benthic settlement and survival of a temperate reef fish. Marine Ecology Progress Series 235:303-309.

Shima, J. S., E. G. Noonburg, and J. B. Phillips. 2010. Life history and matrix heterogeneity interact to shape metapopulation connectivity in spatially structured environments. Ecology 91:12151224. 
Shima, J. S., E. G. Noonburg, and S. E. Swearer. 2015. Consequences of variable larval dispersal pathways and resulting phenotypic mixtures to the dynamics of marine metapopulations. Biology Letters 11:20140778.

Shima, J. S., and C. W. Osenberg. 2003. Cryptic density dependence: effects of covariation between density and site quality in a reef fish. Ecology 84:46-52.

Shima, J. S., C. W. Osenberg, and C. M. St Mary. 2008. Quantifying site quality in a hetergeneous landscape: Recruitment of a reef fish. Ecology 89:86-94.

Shima, J. S., and S. E. Swearer. 2009a. Larval quality is shaped by matrix effects - Implications for connectivity in a marine metapopulation. Ecology 90:1255-1267.

Shima, J. S., and S. E. Swearer. 2009b. Spatially variable larval histories may shape recruitment rates of a temperate reef fish. Marine Ecology Progress Series 394:223-229.

Shima, J. S., and S. E. Swearer. 2010. The legacy of dispersal: Larval experiences shapes persistence later in the life of a reef fish. Journal of Animal Ecology 79:1308-1314.

Shima, J. S., and S. E. Swearer. 2016. Evidence and population consequences of shared larval dispersal histories in a marine fish. Ecology 97:25-31.

Siegel, D. A., S. Mitarai, C. J. Costello, S. D. Gaines, B. A. Kendell, R. R. Warner, and K. B. Winters. 2008. The stochastic nature of larval connectivity among nearshore marine populations. Proceedings of the National Academy of Sciences 105:8974-8979.

Siepielski, A. M., J. D. DiBattista, and S. M. Carlson. 2009. It's about time: The temporal dynamics of phenotypic selection in the wild. Ecology Letters 12:1261-1276.

Smith, A., and J. S. Shima. 2011. Variation in the effects of larval history on juvenile performance of a temperate reef fish. Austral Ecology 36:830-838.

Snover, M. L. 2008. Ontogenetic habitat shifts in marine organisms: Influencing factors and the impact of climate variability. Bulletin of Marine Science 83:53-67.

Sogard, S. M. 1997. Size-selective mortality in the juvenile stage of teleost fishes: A review. Bulletin of Marine Science 60:1129-1157.

Sponaugle, S., J. N. Boulay, and T. L. Rankin. 2011. Growth- and size-selective mortality in pelagic larvae of a common reef fish. Aquatic Biology 13:263-273.

Sponaugle, S., R. K. Cowan, A. Shanks, S. G. Morgan, J. M. Leis, J. Pineda, G. H. Boehlert, M. J. Kingsford, K. C. Lindeman, C. Grimes, and J. L. Munro. 2002. Predicting self-recruitment in marine populations: Biophysical correlates and mechanisms. Bulletin of Marine Science 70:S341-S375.

Sponaugle, S., and K. Grorud-Colvert. 2006. Environmental variability, early life-history traits, and survival of new coral reef fish recruits. Intergrative and Comparative Biology 46:623-633. 
Sponaugle, S., K. Grorud-Colvert, and D. Pinkard. 2006. Temperature-mediated variation in early life history traits and recruitment success of the coral reef Fish Thalassoma bifasciatum in the Florida Keys. Marine Ecology Progress Series 308:1-15.

Sponaugle, S., and D. Pinkard. 2004a. Impact of variable pelagic environments on natural larval growth and recruitment of the reef fish Thalassoma bifasciatum. Journal of Fish Biology 64:34-54.

Sponaugle, S., and D. Pinkard. 2004b. Lunar cyclic population replenishment of a coral reef fish: Shifting patterns following oceanic events. Marine Ecology Progress Series 267:267-280.

Steele, M. A., and G. E. Forrester. 2002. Early post-settlement predation on three reef fishes. Ecology 83:1076-1091.

Stier, A. C., S. W. Geange, and B. M. Bolker. 2013. Predator density and competition modify the benefits of group formation in a shoaling reef fish. Oikos 122:171-178.

Stoks, R., M. De Block, F. Van De Meutter, and F. Johansson. 2005. Predation cost of rapid growth: Behavioural coupling and physiological decoupling. Journal of Animal Ecology 74:708-715.

Sun, Z., J.-F. Hamel, C. C. Parrish, and A. Mercier. 2015. Complex offspring size effects: Variations across life stages and between species. Ecology and Evolution 5:1117-1129.

Sundström, L. F., M. Lõhmus, and R. H. Devlin. 2005. Selection on increased intrinsic growth rates in coho salmon, Oncorhynchus Kisutch. Evolution 59:1560-1569.

Suthers, I. M. 1998. Bigger? Fatter? Or is faster growth better? Considerations on condition in larval and juvenile coral-reef fish. Australian Journal of Ecology 23:265-273.

Svardal, H., C. Rueffler, and M. Doebeli. 2014. Organismal complexity and the potential for evolutionary diversification. Evolution 68:3248-3259.

Swearer, S. E., J. E. Caselle, D. W. Lea, and R. R. Warner. 1999. Larval retention and recruitment in an island population of a coral-reef fish. Nature 402:799-802.

Swearer, S. E., and J. S. Shima. 2010. Regional variation in larval retention and dispersal drives recruitment patterns in a temperate reef fish. Marine Ecology Progress Series 417:229-236.

Taborsky, B., M. Heino, and U. Dieckmann. 2012. Size-dependent mortality and competition interactively shape community diversity. Evolution 66:3534-3544.

Takatsu, K., and O. Kishida. 2015. Predator cannibalism can intensify negative impacts on heterospecific prey. Ecology 96:1887-1898.

Thorson, G. 1950. Reproductive and larval ecology of marine bottom invertebrates. Biological Reviews 25:1-45. 
Tupper, M., and R. G. Boutilier. 1995. Effects of conspecific density on settlement, growth, and postsettlement survival of a temperate reef fish. Journal of Experimental Marine Biology and Ecology 191:209-222.

Tupper, M., and R. G. Boutilier. 1997. Effects of habitat on settlement, growth, predation risk and survival of a temperate reef fish. Marine Ecology Progress Series 151:225-236.

Vigliola, L., P. J. Doherty, M. G. Meekan, D. M. Drown, M. E. Jones, and P. H. Barber. 2007. Genetic identity determines risk of post-settlement mortality of a marine fish. Ecology 88:1263-1277.

Vigliola, L., and M. G. Meekan. 2002. Size at hatching and planktonic growth determine postsettlement survivorship of a coral reef fish. Oecologia 131:89-93.

Warner, D. A., and R. M. Andrews. 2002. Laboratory and field experiments identify sources of variation in phenotypes and survival of hatchling lizards. Biological Journal of the Linnean Society 76:105-124.

Webster, M. 2002. Role of predators in the early post-settlement demography of coral-reef fishes. Oecologia 131:52-60.

Whitten, A. R., N. L. Klaerb, G. N. Tuck, and R. W. Day. 2013. Accounting for cohort-specific variable growth in fisheries stock assessments: A case study from south-eastern Australia. Fisheries Research 142:27- 36.

Wilson, D. T., and M. G. Meekan. 2001. Environmental influences on patterns of larval replenishment in coral reef fishes. Marine Ecology Progress Series 222:197-208.

Wilson, D. T., and M. G. Meekan. 2002. Growth-related advantages for survival to the point of replenishment in the coral reef fish Stagastes partitus (Pomacentridae). Marine Ecology Progress Series 231:247-260.

Wilson, J., and C. W. Osenberg. 2002. Experimental and observational patterns of density-dependent settlement and survival in the marine fish Gobiosoma. Oecologia 130:205-215.

Wormald, C. L., M. A. Steele, and G. E. Forrester. 2013. High population density enhances recruitment and survival of a harvested coral reef fish. Ecological Applications 23:365-373. 